\title{
Ulf Hailer, Aysun Şanlı
}

\section{Gehöfte und kleine ländliche Siedlungen auf dem Gebiet von Kyaneai}

\begin{abstract}
Gehöfte
Das im Hinterland des südtürkischen Küstenortes Kaş auf fast 1000 m üNN aufsteigende Bergland von Yavu bietet insbesondere für die Erforschung der Siedlungsweise in Einzelgehöften wünschenswerte Rahmenbedingungen ${ }^{1}$. Zum einen hat sich in der Region das antike Gehöftenetz einschließlich der zugehörigen Wirtschaftsstrukturen (vor allem Terrassen, Viehgehege, Preß- und Mahlanlagen, Zisternen) aufgrund einer nur spärlichen nachantiken bzw. nachbyzantinischen Siedlungstätigkeit in weiten Teilen erhalten ${ }^{2}$. Zum zweiten fallen die geographischen Ränder des Yavu-Berglandes über weite Strecken mit den Territoriumsgrenzen der zentrallykischen Polis Kyaneai zusammen ${ }^{3}$. Mithin können sämtliche Befunde zur Siedlungsweise in Einzelgehöften in einen historisch-geographischen Bezugsrahmen gestellt werden. Da sich die Gesamtausdehnung des Territoriums relativ genau ermitteln läßt $t^{4}$, besteht Gelegenheit, die Gesamtzahl der in der Chora der Polis Kyaneai wirtschaftenden Einzelgehöfte einigermaßen exakt zu erfassen. Zugleich dürften die antiken Gehöfte der Region einen wohl repräsentativen Überblick über das architektonische Spektrum im lykischen Gehöftbau bieten. Denn der allgemeine Erhaltungszustand gestattet in der Regel nicht nur die Rekonstruktion von Ausdehnung und Grundriß, sondern vermittelt darüber hinaus in vielen Fällen auch eine konkrete Vorstellung von der ursprünglichen bau-

1 Zur Forschungssituation in der Region s. S. $1 \mathrm{ff}$.

2 Nicht mehr zu ermitteln ist der Anteil der aus vergänglichen Werkstoffen errichteten Bauten, d. h. vor allem der Holzbau der Region. Die Holzarchitektur nachahmenden Felsfassaden- und Hausgräber bezeugen eindrücklich, daß Holz als Bau- und Werkstoff gerade im vorhellenistischen Lykien von großer Bedeutung war.

Wieviele antike Einzelgehöfte letztendlich im Zuge der Geländebegehungen nicht registriert wurden, ist kaum exakt zu bestimmen; s. Kolb S. 10.

3 Die Polis Kyaneai wurde wohl im mittleren 4. Jahrhundert v. Chr. nach Auflösung der lykischen Dynastenherrschaften (im Zuge der Niederschlagung des Satrapenaufstandes) eingerichtet, s. oben Beitrag Kolb S. 34. Sehr wahrscheinlich bildete das Yavu-Bergland schon im 6. und 5. Jahrhundert bzw. in der ersten Hälfte des 4. Jahrhunderts v. Chr. in weiten Teilen eine politisch-administrativ geschlossene Siedlungskammer; s. Kolb, Thomsen.

4 S. Kolb S. 5.
\end{abstract}


lichen Erscheinung. Insgesamt bilden die im Bergland von Yavu registrierten Gehöftanlagen eine für den gesamten Mittelmeerraum singuläre Materialbasis, die eine Vielzahl von Fragen zur Siedlungsweise in Einzelgehöften und zum antiken Gehöftbau herausfordert. Die Beschäftigung mit den Gehöften im Bergland von Yavu kann mithin einen substantiellen Beitrag nicht nur zur antiken Siedlungsform ,Einzelgehöft', sondern vor allem auch zum Stellenwert der Chora in ihrer Funktion als Siedlungs- und Wirtschaftsraum leisten:

Welchen Stellenwert nehmen die Einzelgehöfte im Siedlungsgefüge des YavuBerglandes ein? Wann wurden die ersten Einzelgehöfte gebaut? Wie entwickelt sich der Gehöftbau im historischen Wandel? Wieviele Gehöfte wirtschafteten in der Zeit vor Einrichtung der Polis Kyaneai, d.h. in archaisch-klassischer Zeit, als das Yavu-Bergland nach dynastisch-feudalen Prinzipien beherrscht wurde? Und wie verteilen sich die Einzelgehöfte in dieser Zeit im Umland? Lassen sich nach der Konstituierung der Polis Kyaneai im 4. Jahrhundert v. Chr. bezüglich der Zahl und Verteilung der Einzelgehöfte Veränderungen feststellen? Und angesichts des guten Erhaltungszustands vieler Gehöfte: Sind Unterschiede im Gehöftbau zwischen Dynastenzeit und Poliszeit zu erkennen? Läßt das Gehöftmaterial Rückschlüsse auf Wirtschaftsweise/Betriebsformen der Gehöfte zu?

Doch bevor die Entwicklung der Siedlungsweise in Einzelgehöften anhand der gestellten Fragen in freilich nur groben Strichen nachgezeichnet werden soll, sind die Kriterien offenzulegen, nach welchen ein ländlicher Siedlungsplatz im Bergland von Yavu als Einzelgehöft zu kategorisieren ist. Die Frage erscheint nur auf den ersten Blick überflüssig, hat aber angesichts des sehr disparaten Befundmaterials durchaus ihre Berechtigung. Zurecht ist nämlich davor gewarnt worden, unkritisch jeden in ländlicher Einzellage aufgefundenen Baurest sogleich als Ruine eines antiken Bauernhofs zu identifizieren ${ }^{5}$. Und in der Tat registrierten wir auf dem Land eine Vielzahl von einfachen, zumeist nur einräumigen Gebäuden geringer Bauqualität ${ }^{6}$, die keinerlei Indizien für eine dauerhafte Nutzung als Bauernhof aufweisen, wenn auch nicht prinzipiell auszuschließen ist, daß manche dieser Einraumgebäude tatsächlich als sehr ärmliche Bauernstellen dienten. Wahrscheinlicher ist, daß es sich bei solchen Bauresten in der Mehrzahl um Wirtschaftsgebäude im weitesten Sinn handelt?. Methodisch ist eine Festlegung von ,Gehöftkriterien' auch deshalb angeraten, weil bislang in der gesamten Region kein konkretes Schriftzeugnis überliefert ist, das explizit die Nutzung eines ländlichen Siedlungsplatzes als Gehöft bezeugt ${ }^{8}$. Somit stützt sich die Funktionsbe-

${ }^{5}$ R. Osborne, in: B. Wells (Hrsg.), Agriculture in Ancient Greece (Stockholm 1992) 21-25; Diskussionsprotokoll ebd. 58-61.

${ }^{6}$ Es geht um ca. 50-60 Bauten, deren in den meisten Fällen wohl nur sockelhohe Aufmauerung aus einfachem und lose geschichtetem Bruchsteinmauerwerk bestand.

7 Denkbar ist eine Nutzung als externe Speicher/Scheune oder auch als nur temporär genutzter Unterstand oder Geräteschuppen für die auf den Äckern und Terrassen arbeitende Landbevölkerung.

8 Angesichts der Selbstverständlichkeit dieser Existenzform ist mit einer solchen Praxis auch kaum zu rechnen. Ein indirektes Schriftzeugnis bilden die Grabinschriften auf Sarkophagen, 
stimmung der im Bergland von Yavu entdeckten ländlichen Siedlungsplätze - ob Dorf, Weiler oder Gehöft - ausschließlich auf den Oberflächenbefund. Leider steht bis zum jetzigen Zeitpunkt noch kein stratifiziertes, d.h. durch reguläre Ausgrabungen bzw. Sondagen gewonnenes Fundmaterial zur Verfügung, das nicht nur Informationen zum Funktionszusammenhang eines Gehöfts, d.h. beispielsweise über die Nutzung einzelner Räume, sondern vor allem auch abgesicherte Hinweise zum Baudatum bzw. zur Nutzungsdauer liefern könnte (s.u.). Die im Oberflächenbefund zu erkennenden archäologischen Indizien, welche eine Deutung als Einzelgehöft unterstützen, treten in der Regel nicht vereinzelt, sondern in Kumulierung auf. Die Vielfalt der archäologischen Merkmale spiegelt gewissermaßen die Komplexität des bäuerlichen Alltags wider.

Folgende Befundmerkmale rechtfertigen die Bestimmung eines ländlichen Siedlungsbefundes als Einzelgehöft:

1) eine komplexe Grundrißanordnung, die im Gebäudebestand oder aufgrund einer differenzierten Binnengliederung eine Unterscheidung in Kern- und Nebenbauten (Wohnbau, Wirtschaftsgebäude, Hofbereich) erkennen läßt und damit das breite Funktionsspektrum einer gegliederten Haushaltsorganisation, wie sie der bäuerliche Alltag erfordert, reflektiert.

2) ein architektonisch aufwendig errichteter Kernbau ${ }^{9}$ - erkennbar an der im Vergleich zu den Nebenbauten höheren Aufmauerung in Stein ${ }^{10}$, an der besseren Bearbeitung der Mauerblöcke und der Verwendung konstruktiv-ästhetischer Bauelemente (z. B. Randschlag, Schmuckbossen). Je repräsentativer ein ländliches Ensemble gestaltet wurde, desto wahrscheinlicher ist es, daß es sich um das auf dem Land liegende Lebenszentrum einer Gutsbesitzerfamilie handelte. Der Repräsentationscharakter solcher Gehöftbauten erschließt sich nicht nur aus einer elaborierten Mauergestaltung bzw. Steinbearbeitung, sondern oftmals auch aus besonders aufwendig gestalteten Türen, die zudem in vielen Fällen mit ausgeklügelten, nur von innen zu verriegelnden Verschlußvorrichtungen ausgestattet wurden, was m. E. ebenfalls einen klaren Anhaltspunkt für eine nicht nur saisonale Wohnnutzung darstellt; für eine nur zeitweise oder saisonal bewohnte Anlage oder ein ausschließlich wirtschaftlich genutztes Gebäude erscheint ein solcher Bauaufwand unverhältnismäßig.

3) Einzel- bzw. Familiengräber in der Nachbarschaft eines ländlichen Baukomplexes. Grabanlagen weisen einen Siedlungsplatz als Heimstatt bzw. Lebenszentrum einer auf dem Land lebenden Familie/Sippe aus.

4) im Kontext und in der Nachbarschaft ländlicher Komplexe befindliche Wirtschaftsinstallationen. Im Yavu-Bergland sind dies vor allem Zisternen, Preßanla-

die in unmittelbarer Nachbarschaft oder in der Nähe von Gehöften stehen und deshalb als zugehörige Grablegen für die dort lebenden Bauernfamilien zu verstehen sind.

${ }^{9}$ S. unten exemplarisch Abb. 8 auf S. 229.

10 Für die Nebengebäude wurde bei den meisten Gehöften ein geringerer Bauaufwand betrieben: Die Aufmauerung in Stein beschränkt sich auf wenige Schichten (Sockelhöhe), die Mauerblöcke besaßen kleinere Formate und wurden in der Regel weniger sorgfältig bearbeitet. 
gen, Mahltassen und Mühlsteine, welche den Wirtschaftscharakter eines ländlichen Ensembles ebenso bezeugen wie unmittelbar angeschlossene bzw. im näheren Umfeld liegende Terrassenkomplexe und Viehgehege. Schon der Aufwand, der beispielsweise bei Anlage und auch Pflege einer aus dem Fels gehauenen $\mathrm{Zi}$ sterne oder Preßanlage betrieben werden mußte, sowie der schiere Wert der landwirtschaftlichen Installationen sprechen für den Wohncharakter der benachbarten Bauten ${ }^{11}$.

5) Oberflächenkeramik und Ziegelfragmente im Bereich ländlicher Baukomplexe deuten ebenfalls auf einen ganzjährig auf dem Land lebenden Haushalt hin, insbesondere wenn Gefäßfragmente in größerer Zahl und unterschiedlicher Gattungen (Fein- und Küchenware) vorliegen.

Von entscheidender Bedeutung für die Rekonstruktion der antiken Siedlungsgeschichte des Yavu-Berglandes ist die Datierung der Einzelgehöfte. Wie schon angedeutet, stützt sich die zeitliche Einordnung der Gehöfte, d.h. die Bestimmung von Baudatum und Nutzungsdauer, ausschließlich auf den Oberflächenbefund.

- Dabei kommt der Beurteilung der Mauergestaltung entscheidende Bedeutung zu. Es hat sich gezeigt, daß die anhand lykischer Wehr- und Repräsentationsbauten erstellte Chronologie der Mauerstile auch für den lykischen Gehöftbau Gültigkeit besitzt ${ }^{12}$. Infolgedessen sind wir nicht nur in der Lage, archaische und klassische Gehöfte anhand der Mauergestaltung ${ }^{13}$ von hellenistischen und kaiserzeitlichen Gehöften klar zu scheiden. Es ist inzwischen auch gelungen, einige wesentliche Kennzeichen des archaischen Gehöftbaus zu isolieren und somit Gehöfte der frühen Dynastenzeit von solchen der späteren zu unterscheiden. Außerdem hat sich in der Zusammenschau der in der Region entdeckten hellenistisch-kaiserzeitlichen Gehöfte gezeigt, daß sicher in die Kaiserzeit zu datierende Gehöftanlagen bautechnische Eigenheiten aufweisen können, die bei hellenistischen Komplexen nicht anzutreffen sind ${ }^{14}$.

- Im Bereich eines Gehöfts abgesammelte signifikante Oberflächenkeramik kann ein architektonisch begründetes Baudatum bestätigen, gibt aber in erster Linie Auskunft über bestimmte Nutzungsphasen ${ }^{15}$.

11 Produktionsanlagen wie Oliven-/Weinpressen wurden mit wertvollen, heute nicht mehr nachweisbaren Holzvorrichtungen (Preßbaum, Preßzug) betrieben, wobei außerdem ein gewisser Anteil an Metallteilen vorauszusetzen ist. Solche Gerätschaften dürften je nach Standort entweder an Ort und Stelle oder im benachbarten Gehöft gelagert worden sein.

12 Die Kennzeichen der im vorrömischen Lykien verwendeten Mauertechniken und -stile wurden von Th. Marksteiner anhand der lykischen Befestigungsarchitektur herausgearbeitet und in eine chronologische Abfolge gestellt: Th. Marksteiner, Die befestigte Siedlung von Limyra (Wien 1994) 119-133; 165-168.

13 Aber auch anhand anderer Kriterien wie Grundrißdisposition und Standortwahl (s. u. S. 224f.).

14 Die für die kaiserzeitlichen Gehöfte verwendeten Mauersteine besitzen in der Regel kleinere quaderhafte Formate, während hellenistische Gehöftmauern in vielen Fällen aus mittelgroßen Blöcken mit unregelmäßigem (polygonalisierendem) Umriß bestehen. Zeitlich noch nicht exakt fixiert ist der Ubergang von ,echtem' hellenistischem Läufer-Binder-Mauerwerk zu kaiserzeitlichem Kleinquadermauerwerk.

15 Zur Aussagekraft der Oberflächenkeramik s. Kolb S. 10-12. 
- Im Nahbereich bzw. im Umfeld von Gehöften liegende Einzel- oder Familiengräber können ein für die Nutzungszeit einzelner Gehöfte wichtiger Anhaltspunkt sein - allerdings nur dann, wenn es sich um Grabtypen handelt, die chronologisch sicher eingeordnet werden können ${ }^{16}$.

Im Regelfall stützt sich also die Datierung eines Gehöfts auf unterschiedliche Anhaltspunkte, wobei die Gehöftarchitektur - Mauergestaltung und Gesamtanlage - das grundlegende Kriterium bildet; steht signifikante Oberflächenkeramik zur Verfügung und/oder wurden zugehörige Gräber registriert, besitzen wir zusätzliche Datierungen, die freilich für sich genommen Nutzungsphasen dokumentieren, aber nicht unbedingt den Zeitpunkt der Errichtung des betreffenden Gehöfts ${ }^{17}$.

Gehöftestatistik (Baudatum)

\begin{tabular}{|c|c|c|c|}
\hline Epochen/Gehöfttypen & Turmgehöfte & Gehöfte ohne Turm & Gesamt \\
\hline $\begin{array}{l}\text { Archaische Zeit } \\
\text { (6.Jh. v. Chr.) }\end{array}$ & - & 10 & 10 \\
\hline $\begin{array}{l}\text { Klassische Zeit } \\
\text { (5./4. Jh. v. Chr.) }\end{array}$ & 44 & 88 & 132 \\
\hline $\begin{array}{l}\text { Hellenistische Zeit/ } \\
\text { Frühe Kaiserzeit }\end{array}$ & 88 & 104 & 192 \\
\hline Mittlere und späte Kaiserzeit & 5 & 51 & 56 \\
\hline $\begin{array}{l}\text { Zahl Turmgehöfte/ } \\
\text { Gehöfte ohne Turm }\end{array}$ & 137 & 252 & $\begin{array}{l}389 \text { (41 Gehöfte } \\
\text { nicht datierbar) }\end{array}$ \\
\hline
\end{tabular}

Gehöfrestatistik (Gehöfte gleichzeitig in Nutzung)

\begin{tabular}{llll}
\hline Epochen/Gehöfttypen & Turmgehöfte & Gehöfte ohne Turm & Gesamt \\
\hline Archaische Zeit (6.Jh. v. Chr.) & - & $10-12(?)$ & $10-12($ ?) \\
Klassische Zeit (5./4. Jh. v. Chr.) & 44 & 96 & 140 \\
Hellenistische Zeit/ & 97 & 118 & 215 \\
Frühe Kaiserzeit & 93 & 154 \\
Mittlere und späte Kaiserzeit & 61 & 93 & \\
\hline
\end{tabular}

${ }^{16}$ Die regionalen Gräber und Grabformen werden von Oliver Hülden im Rahmen einer Dissertation bearbeitet und geordnet. Obwohl die ,Laufzeiten' der einzelnen Grabtypen bislang nicht exakt eingegrenzt werden können, steht die Abfolge der Genese der bislang identifizierten ländlichen Grabformen fest: Tumulusgräber, gebaute Kammergräber und Hausgräber (zu letzterem erst durch die Arbeiten auf dem Avşar Tepesi erschlossenen lykischen Grabtyp s. A. Thomsen zit. S. 13 Anm. 24) sowie aus dem Fels geschlagene Hausgräber und die spätestens ab $400 \mathrm{v}$. Chr aufkommenden Felsfassadengräber sind die charakteristischen Grabtypen der Dynastenzeit (6.-4. Jahrhundert v. Chr.). Die mit Gehöften assoziierten Sarkophage sind gemäß den inschriftlich datierten Exemplaren wohl ausschließlich hellenistisch-kaiserzeitlichen Datums.

17 Oberflächenkeramik und Einzelgräber gewinnen an Datierungskraft, wenn der Erhaltungszustand der Baureste keine Einordnung zuläßt. 
In der im folgenden skizzierten Geschichte der Siedlungsweise in Einzelgehöften stehen vor allem siedlungsarchäologische Gesichtspunkte im Vordergrund: 1. Zahl und Verteilung der Gehöfte in der Chora; 2. die Gehöftstandorte 3. die Kennzeichen des regionalen Gehöftbaus; 4. Überlegungen zur Gehöftwirtschaft. Dabei geht es in erster Linie um das statistisch gestützte Aufzeigen regionaler Entwicklungslinien, weniger um eine an dieser Stelle nicht zu leistende detaillierte Materialvorlage.

Auf den rund 100 erforschten Quadrakilometern wurden ca. 430 ländliche Baukomplexe registriert, die gemäß der oben aufgelisteten Kriterien als Einzelgehöfte zu deuten sind ${ }^{18}$. Rund 140 Einzelgehöfte sind wohl archaisch-klassischen Baudatums, wurden also in einer Epoche errichtet, als das Yavu-Bergland von feudalaristokratischen Strukturen geprägt war ${ }^{19}$. Wie ein Blick auf die Siedlungskarte mit den archaisch-klassischen Siedlungsplätzen zeigt (Abb. 4 auf S. 16f.), verteilen sich die dynastenzeitlichen Gehöftanlagen (6.-4. Jahrhundert v. Chr.) nicht gleichmäßig über die Region. Vielmehr ist eine auffällige Konzentration um den größten Zentralort des Berglandes, um die Dynastensiedlung auf dem Avşar Tepesi zu erkennen. Im Umland der übrigen, ebenfalls bereits in vorhellenistischer Zeit prosperierenden, kleineren Burgsiedlungen von Tüse, Korba, Trysa, Hoyran und Kyaneai fehlt eine entsprechend dichte ländliche Besiedlung bzw. ein ebenso dichter Gürtel aus Einzelgehöften ${ }^{20}$. Die aus der zentralen geographischen Lage, der Siedlungsgröße und der Qualität der Bausubstanz erschlossene Bedeutung des Avşar Tepesi als Vorort und Machtzentrum in vorhellenistischer Zeit ${ }^{21}$ wird durch das engmaschige Gehöftenetz in seinem Umfeld eindrücklich bestätigt.

Die Aufsiedlung des Berglandes, d.h. das Aufkommen der Siedlungsweise in Einzelgehöften, setzt in archaischer Zeit ein ${ }^{22}$. Von den 142 vorhellenistischen Gehöften ist nur für 10 bis 12 Anlagen ein archaisches Baudatum nachweisbar, die gemäß der bei sieben Komplexen registrierten Oberflächenkeramik sowie der vergleichbaren Bauweise der restlichen Anlagen sämtlich im 6. Jahrhundert v. Chr. errichtet worden sein dürften. Es ist zu vermuten, daß wir mit den 10 bis 12 archaischen Gehöften nicht den vollständigen vorklassischen Gehöftbestand im bislang erforschten Gebiet erfaßt haben. Sicherlich sind uns im dicht überwachsenen Gelände manche Anlagen aufgrund ihres allzu rudimentären Erhaltungszustandes entgangen ${ }^{23}$, und es ist vor allem damit zu rechnen, daß eine nicht näher zu bestimmende Zahl archaischer Gehöfte im Zuge einer späteren

18 Die Gesamtfläche des Forschungsgebiets und Polisgebiets beträgt ca. 136 Quadratkilometer.

19 S. Thomsen S. 30.

20 Neben den 142 archaisch-klassischen Einzelgehöften wurden im bislang erforschten Gebiet sieben weiler- oder dorfartige ländliche Kleinsiedlungen jener Epoche entdeckt. Diese werden unten S. 234 im Beitrag von A. Şanlı besprochen.

${ }^{21}$ s. Kolb-Thomsen S. 30-34.

22 Indizien für eine vorarchaische ländliche Besiedlung gibt es bislang nicht.

${ }^{23} \mathrm{Zu}$ den Forschungsbedingungen bei den systematischen Begehungen im Yavu-Bergland s. Kolb S. 9 f. 
Überbauung zerstört wurde; dies ist umso wahrscheinlicher, als sich die beim Neubau eines Gehöfts relevanten Standortkriterien in klassischer Zeit nicht änderten (s.u.). Aber auch wenn die Gehöftdichte in archaischer Zeit kaum mehr exakt zu rekonstruieren ist, so dürfte die geringe Zahl der Einzelgehöfte eine in der Tat nur spärliche ländliche Besiedlung in archaischer Zeit widerspiegeln.

Mit Ausnahme einer südlich von Korba liegenden Anlage sind alle bislang entdeckten archaischen Einzelgehöfte dem näheren und weiteren Umland der Dynastensiedlung auf dem Avşar Tepesi zuzurechnen ${ }^{24}$. Sicherlich handelt es sich hierbei um keine zufällige Befundsituation, vielmehr ist der räumliche Bezug der meisten archaischen Einzelgehöfte zum Avşar Tepesi ein Zeugnis für dessen schon für das 6. Jahrhundert v. Chr. vorauszusetzende Zentralortstellung zu werten ${ }^{25}$. Es fällt auf, daß alle archaischen Gehöfte auf Berg-/Hügelkuppen oder in Spornlage gebaut wurden, d.h. in exponierten Lagen, die eine Kontrolle des Umfelds gestatteten und zugleich eine günstige Verteidigungsposition boten; eine besondere Rolle spielte bei der Standortwahl offensichtlich auch die Anbindung an Überlandwege, denn alle bislang registrierten archaischen Einzelgehöfte liegen an wichtigen regionalen Verkehrswegen. Bemerkenswert ist außerdem, daß fast alle archaischen Anlagen in Sichtverbindung mit der Dynastensiedlung auf dem Avşar Tepesi stehen, was möglicherweise als Indiz für eine strategische Funktion der archaischen Gehöfte zu werten ist. Auch wenn konkrete Zeugnisse fehlen, ist nicht auszuschließen, daß sich die verhältnismäßig wenigen auf dem Land lebenden Hofherren im Interesse des Zentralorts zur Kontrolle des Landgebiets verpflichteten; insbesondere die in Grenznähe liegenden Höfe dürften in diesem Zusammenhang eine besondere Verantwortung getragen haben. Optische und akustische Meldesignale (Feuer/Rauch, Schall) könnten dabei einen im Ernstfall lebenswichtig schnellen Informationsfluß zwischen den Gehöftanlagen und dem Zentralort gesichert haben.

Allerdings soll hier keine Lanze für einen schon in archaischer Zeit existierenden Ring von ,Landfestungen' gebrochen werden, dessen einziger Zweck der Schutz der Dynastensiedlung gewesen wäre. Für die archaische Zeit fehlen regelrechte Umlandfestungen $\mathrm{m}$. W. nicht nur im Befundbild des archaischen YavuBerglandes, sondern auch sonst im östlichen Mittelmeerraum. Aber gerade dieser negative Befund spricht für eine Doppelfunktion der archaischen Umlandgehöfte, deren Besitzer zwar in erster Linie Viehzucht und Ackerbau betrieben, zugleich aber auch im Eigen- und Allgemeininteresse Wacht- und Kontrollaufgaben im Vorfeld des Zentralortes erfüllten. Daß die Lebensverhältnisse in archaischer Zeit, als das Umland nur dünn besiedelt war, tatsächlich prekär waren, zeigt sich aber nicht nur in der Verteilung der Standorte, sondern auch an den Kennzeichen des zeitgenössischen Gehöftbaus.

${ }^{24}$ Ein Gehöft wurde nur ca. $150 \mathrm{~m}$ von der klassischen Siedlung entfernt gebaut, vier weitere Komplexe liegen ca. $2-4 \mathrm{~km}$ von der Siedlung entfernt.

${ }^{25} \mathrm{~S}$. Thomsen S. $30 \mathrm{ff}$. 


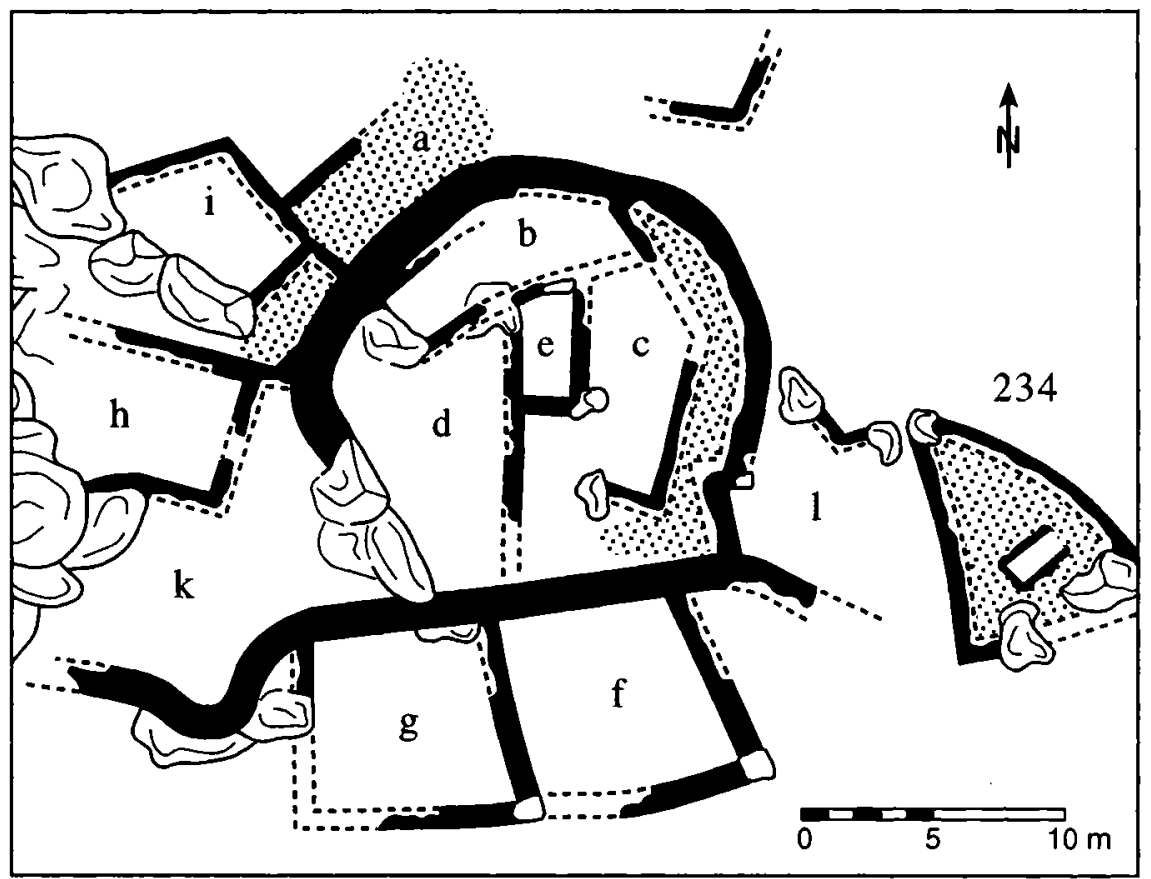

Abb. 1: Grundriß eines archaischen Gehöftes südwestlich des Avşar Tepesi.

Als Beispiel für ein archaisches Gehöft wird im folgenden ein Komplex aus dem nächsten Umfeld des Avşar Tepesi, genauer: südöstlich des Burgbergs vorgestellt, der die charakteristischen Baumerkmale archaischer Gehöftanlagen vereint (Abb. 1). Das Gehöft wurde auf einer im Nordwesten von hohen Felsen umstandenen, niedrigen Hügelkuppe errichtet, die eine Sichtkontrolle des Umfelds erlaubt. Zugleich bieten die den Gehöftbereich überragenden Felsen einen geeigneten Wetterschutz, vor allem im Winter, wenn die kalt-feuchten Stürme, aus nordwestlicher Richtung vom lykischen Taurus kommend, das Yavu-Bergland erfassen.

Im Grundriß ist der Komplex am Avşar Tepesi, wie auch die übrigen archaischen Gehöftanlagen, auffällig kompakt angelegt, wobei die sichelförmige Führung der streckenweise über $2 \mathrm{~m}$ starken Außenmauern des Kernbaus an die aus Karien bekannten Compound-Anlagen erinnert ${ }^{26}$. Allerdings ist der Innenbe-

${ }^{26}$ Die karischen Compound-Gehöfte wurden erstmals zusammenfassend vorgestellt von W. Radt, Siedlungen und Bauten auf der Halbinsel von Halikarnassos (Tübingen 1970) 145-183. Eine wirtschafts- und sozialgeschichtliche Einordnung der Compound-Anlagen in Karien und in der Megaris bietet H. Lohmann, in: W. Eder, K.-J. Hölkeskamp, Volk und Verfassung im vorhellenistischen Griechenland. Festschrift für Karl-Wilhelm Welwei (Stuttgart 1997) 63-88. 
reich des lykischen ,Compound' weniger stark reguliert, bei der Gehöftanlage am Avşar Tepesi scheint die gebogene Mauerführung eine klare Innenaufteilung verhindert zu haben. Eine stärker regulierte Gliederung ist im Gehöftbau des YavuBerglandes erst seit dem 5. Jahrhundert v. Chr. zu beobachten.

$\mathrm{Da}$ die eher unschematische und von kurvilinearen Mauerstrecken geprägte Bauweise wohl kennzeichnend für die Frühphase des lykischen Gehöftbaus ist, fassen wir mit den im 6. Jahrhundert v. Chr. errichteten Gehöften wohl tatsächlich den Beginn der ländlichen Streubesiedlung im Yavu-Bergland. Die exponierten Gehöftstandorte sowie die sehr wehrhafte Bauweise der archaischen Einzelgehöfte bezeugen dabei unsichere Lebensverhältnisse in der Chora: Viehdiebe und Raubtiere dürften im Alltag die Hauptgefahr für die Landbevölkerung gewesen sein. Wie bei den karischen Compound-Gehöften orientierte sich auch die Bauweise der mit befestigten Gehegen ausgestatteten archaischen Einzelgehöfte im Yavu-Bergland an den Bedürfnissen von Viehzucht und Weidewirtschaft. Daß der in enger Nachbarschaft zur Dynastensiedlung errichtete Komplex tatsächlich das Lebenszentrum eines ,Viehbauern ' bildete, bezeugt das dem Haupteingang östlich vorgelagerte Tumulus-Grab mit dreieckiger Grundform.

In klassischer Zeit - verstärkt wohl seit der zweiten Hälfte des 5. Jahrhunderts und insbesondere im 4. Jahrhundert v. Chr. - scheint die Aufsiedlung des YavuBerglandes in eine dynamische Phase getreten zu sein. In diesem Zeitraum wurde die Mehrzahl der vorhellenistischen Einzelgehöfte erbaut, wobei im näheren und weiteren Umfeld des Avşar Tepesi sogar ein regelrechter ,Bauboom' eingesetzt zu haben scheint ${ }^{27}$. Um den Burgberg ensteht ein Gürtel von Gehöften beachtlicher Größe und Bauqualität. Vor allem im nördlichen Vorfeld des Avşar Tepesi wird nur wenige hundert Meter von der Dynastensiedlung entfernt wohl schon im Verlauf der ersten Hälfte des 5. Jahrhunderts v. Chr. eine Reihe von größeren, repräsentativ gebauten Einzelgehöften errichtet.

Ein eindrucksvolles Beispiel für einen solchen (früh-)klassischen Gutshof stellt ein ca. $300 \mathrm{~m}$ von der Akropolis des Avşar Tepesi entfernt gelegener Komplex dar (Abb. 2), der zu den größten klassischen Gehöftanlagen der Region zählt ${ }^{28}$. Wie die meisten der im näheren Umland des Avşar Tepesi gebauten Einzelgehöfte besitzt auch diese vielräumige Anlage keinen ausgeprägten Wehrcharakter. Die Anlage ist im Grundriß vergleichsweise offen angelegt, die Außenmauern wurden nicht besonders verstärkt. Daß der Hofherr dem Verteidigungsaspekt bei der Entscheidung über den Bauplatz tatsächlich keine Priorität zugestanden hat, zeigt sich auch darin, daß man nicht den unter fortifikatorischen Gesichtspunkten viel besser geeigneten, steil aufragenden Nachbarhügel zum Gehöftstandort bestimmte, sondern die für defensive Zwecke untaugliche Lage unmittelbar oberhalb eines Geländesattels an einem gut ausgebauten Weg. Die hier lebenden Hofherren fühlten sich in der Nachbarschaft zur Dynastensiedlung anscheinend

27 S. Kolb, Thomsen mit Abb. 4.

28 Die Gesamtausdehnung des bebauten Areals beträgt ca. $40 \mathrm{~m} \times 35 \mathrm{~m}$. 


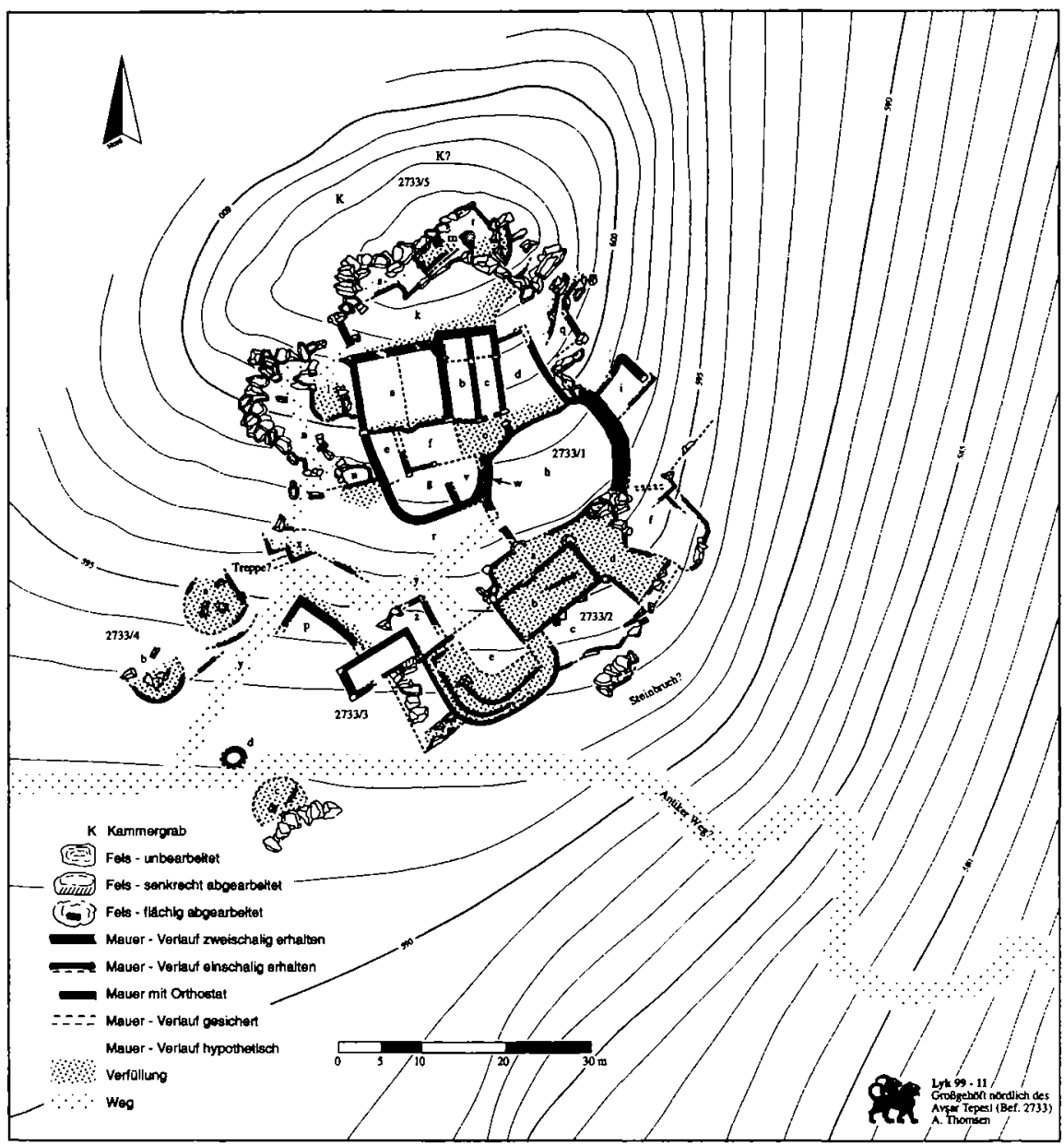

Abb. 2: Grundriß eines (früh)klassischen Gehöftes nördlich des Avşar Tepesi.

relativ sicher; die räumliche Nähe bot im Ernstfall die Möglichkeit zur schnellen Flucht hinter die Mauern des Zentralortes.

Der nur wenige Meter unterhalb des Gehöfts aufgeschüttete und mit letzterem architektonisch eng verbundene monumentale Tumulus ${ }^{29}$ bezeugt den Residenzcharakter der Anlage, die offensichtlich das Lebenszentrum einer der bedeutendsten Familien im Yavu-Bergland des 5. Jahrhunderts v. Chr. bildete. Wohlstand und Rang des Hofherrn beruhten dabei wohl in großem Maß auf Viehzucht und

${ }^{29}$ Sein Durchmesser beträgt ca. $11 \mathrm{~m}$. 
Weidewirtschaft, denn die am stärksten befestigte Gehöftkomponente ist ein massiv ummauerter Hof, der, wie schon für die archaischen Anlagen vermutet, in erster Linie wohl der Unterstellung von Kleinvieh (Ziegen, Schafe) diente. Die aus der Weidewirtschaft resultierenden Produkte (Fleisch, Wolle, Käse) wurden sicherlich in der benachbarten Dynastensiedlung verhandelt, wo der zentrale Markt des Berglandes eingerichtet worden sein dürfte.

Aber nicht nur im Umfeld des Avşar Tepesi erhöht sich in klassischer Zeit die Zahl der Einzelgehöfte, sondern überraschenderweise auch im Südwesten des Yavu-Berglandes (Abb. 4 auf S. 16f.) - überraschend, weil die hier auf fast $900 \mathrm{~m}$ aufsteigende Kırandağ1-Region für bäuerliche Betriebe nicht sonderlich geeignet erscheint. Das Kırandağ1-Bergland bildet in der Geographie des Yavu-Berglandes eine abgeschlossene Landschaftskammer, besitzt teilweise Gebirgscharakter und weist infolgedessen nur relativ wenige und kleinräumige Ackerebenen auf. Dennoch registrierten wir in diesem Gebiet für die klassische Zeit die nach der Avşar-Tepesi-Region zweithöchste Gehöftdichte ${ }^{30}$. Da die landwirtschaftliche Attraktivität für die hohe Siedlungsdichte kaum allein ausschlaggebend gewesen sein dürfte, müssen andere Motive eine maßgebliche Rolle gespielt haben. Wir wissen, daß in hellenistischer Zeit die Südwestgrenze der Polis Kyaneai im Bereich des Kırandağ ${ }_{1}$ verlief ${ }^{31}$, und es ist zumindest wahrscheinlich, daß bereits in vorhellenistischer Zeit im Bereich des Kırandağı die Interessenssphären angrenzender Dynastenherrschaften kollidierten, nämlich diejenigen des Avşar Tepesi, von Phellos und von Isinda ${ }^{32}$. In diesem Kontext ist die im Südwesten des Yavu-Berglandes konstatierte große Zahl klassischer Gehöfte vielleicht als Resultat einer gewissermaßen siedlungspolitischen Maßnahme zu verstehen, wobei aufgrund der räumlichen Nähe wohl vor allem an den Avşar Tepesi als Initiator $\mathrm{zu}$ denken ist. Ziel dieser Maßnahme könnte die Manifestierung von Gebietsansprüchen in dieser unter strategischen und verkehrsgeographischen Gesichtspunkten wichtigen Gebirgsregion gewesen sein, und damit letztendlich die Sicherung der Südwestflanke des zum Avşar Tepesi gehörenden Territoriums $^{33}$.

Daß die Kırandağı-Region in der Tat prekäres Grenzland war, bezeugt die defensive Bauweise vieler der zwischen Kirandağ 1 und Kızılalan Tepesi errichteten vorhellenistischen Gehöfte. Von den insgesamt 25 klassischen Einzelgehöften besitzen allein zehn einen massiven, wohl als Turmhaus zu rekonstruierenden Kern-

30 Verf., in: Lykische Studien 5 (im Druck) und Lykische Studien 6 (im Druck).

$31 \mathrm{M}$. Zimmermann, Untersuchungen zur historischen Landeskunde von Zentrallykien (Bonn 1992) 80-83.

32 S. Kolb-Thomsen S. $30 \mathrm{ff}$. Überlegungen zur politischen Geographie des dynastenzeitlichen Yavu-Berglandes stellt A. Thomsen in seiner S. 13 Anm. 24 zitierten Veröffentlichungen der Dynastensiedlung auf dem Avşar Tepesi an.

33 Als moderne Analogie kann vielleicht die Besetzung der Golanhöhen durch israelische Siedler dienen. Auch dort soll die Präsenz von Farmern Gebietsansprüche untermauern, wobei ebenfalls mit sicherheitspolitischen Sachzwängen argumentiert wird. War die KırandağıRegion in der lykischen Dynastenzeit ähnlich umstritten? 


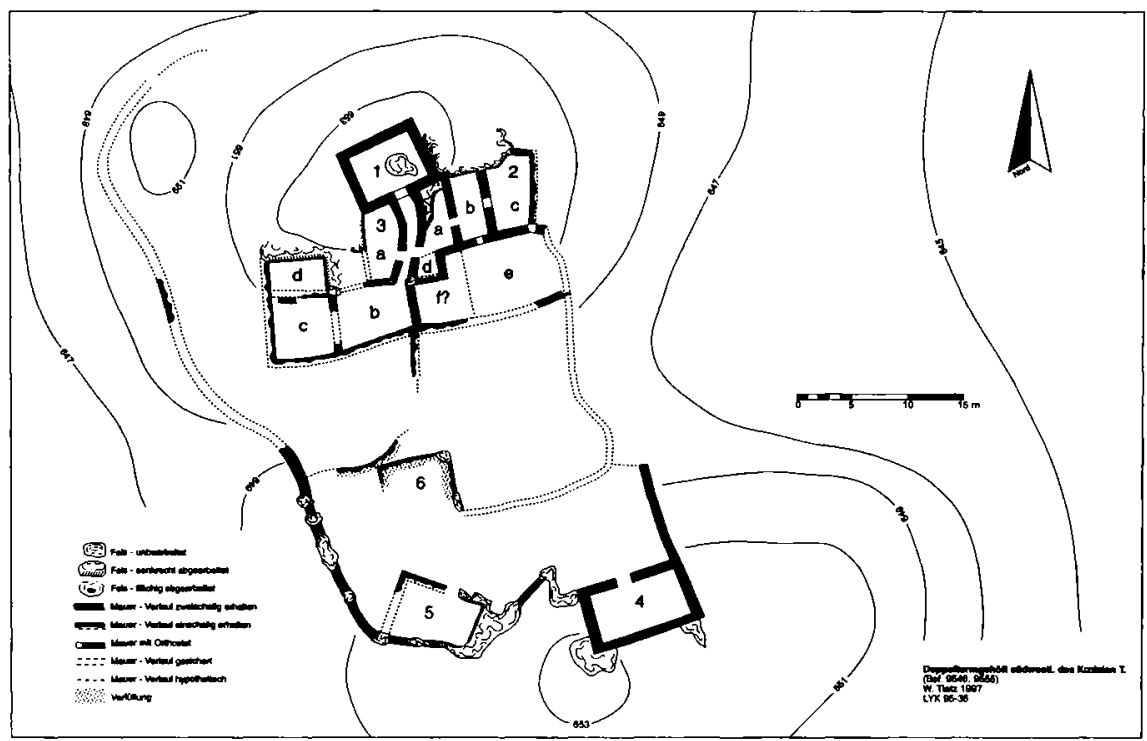

Abb. 3: Grundriß eines klassischen Turmgeböftes im Kizzlalan-Gebiet.

bau $^{34}$ (Abb. 3). Damit weist die Kırandağı-Region auch die höchste Dichte an Turmgehöften in unserem Forschungsgebiet auf, während beispielsweise im unmittelbaren Umfeld des Avşar Tepesi nur zwei klassische Turmgehöfte verzeichnet wurden. Wie schon angedeutet, erübrigte sich offensichtlich eine stärkere Befestigung für die in der Nachbarschaft zur Dynastensiedlung liegenden Einzelgehöfte.

Die unterschiedlichen Grundrißanlagen klassischer Gehöfte vermitteln eine Eindruck von der zeitgenössischen Vielfalt ländlicher Wohn- und Bauformen einer Vielfalt, die im übrigen die Erstellung einer umfassenden Typologie, in der jedes der bislang registrierten Einzelgehöfte einer eindeutig definierten Gruppe zugewiesen werden kann, nicht zuläßt. Das ist allerdings bei einer Alltags- und Nutzarchitektur nicht weiter verwunderlich. Zwar folgt die Mehrzahl der Gehöfte dem Grundmuster ,Kern-/Wohnbau - Nebengebäude/Wirtschaftsgebäude - Hof'. Aber die Anordnung dieser Komponenten war wohl vor allem von der topographischen Situation und den spezifischen Vorgaben des bäuerlichen Alltags abhängig und notwendigerweise entsprechend variabel.

Auf jeden Fall bewährt hat sich die Grundunterscheidung in Gehöfte mit Turmhaus und solche ohne Turmhaus, zumal die Turmgehöfte mit Ausnahme einiger Großgehöfte im Umfeld des Avşar Tepesi in der Regel in besserer Bauqualität ausgeführt wurden, d. h. die Unterscheidung scheint zugleich einen unter- 


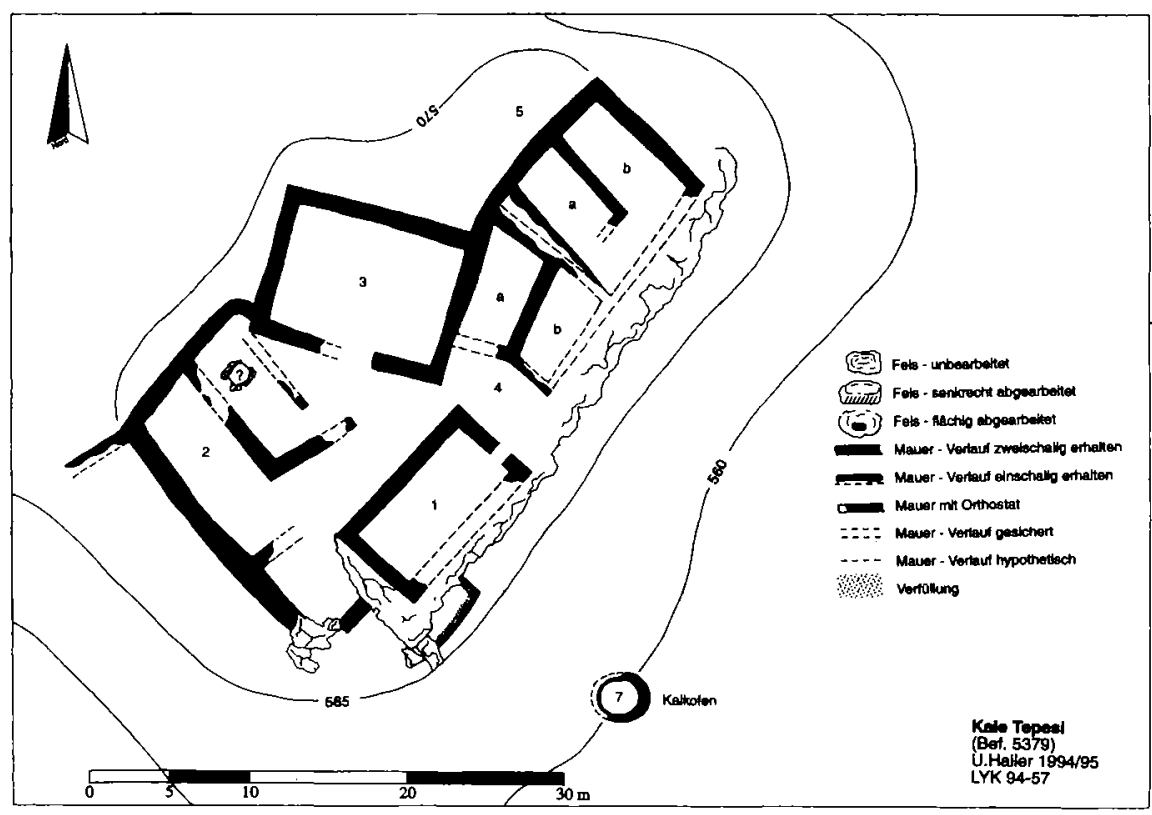

Abb. 4: Grundriß des klassischen Turmgeböftes auf dem Kale Tepesi.

schiedlichen sozialen Rang der Hofbesitzer zu dokumentieren. Bisweilen scheint man sogar besonders repräsentative Bauformen des Zentralortes in die Chora übernommen zu haben ${ }^{35}$. Als anschauliches Beispiel kann hierfür das wehrhafte, wohl in der ersten Hälfte des 4. Jahrhunderts v. Chr. errichtete Turmgehöft auf dem Kale Tepesi dienen ${ }^{36}$ (Abb. 4). Den Kernbau der Anlage bildet ein langrechteckiger Turm, wie er in monumentalerer Ausführung seit ungefähr 400 v. Chr. ebenfalls auf lykischen Akropoleis aufkommt. Ein turmartiger Kernbau mit langrechteckigem Grundriß wurde im Yavu-Bergland bei insgesamt vier Gehöftanlagen registriert ${ }^{37}$, die sich sämtlich durch eine repräsentative architektonische Erscheinung auszeichnen. Mithin könnte sich in der Übernahme dieser Bauform ein besonders hoher sozialer Rang des Besitzers manifestieren. Daß die klassischen Turmgehöfte in der Tat eine exklusive ländliche Wohnform waren, zeigt auch das Zahlenverhältnis: 44 klassischen Turmgehöften stehen 88 turmlose Bauernhöfe gegenüber.

35 Th. Marksteiner, in: F. Blakolmer u.a. (Hrsg.), Fremde Zeiten. Festschrift für Jürgen Borchhardt (Wien 1996) $92 \mathrm{f}$. (klassisches Gehöft mit langrechteckigem Turmgrundriß bei Asar Önü auf dem Gebiet von Limyra).

36 Verf., in: Lykische Studien 4, 225-241.

37 Eine weitere Anlage wurde auf dem Gebiet von Limyra entdeckt, s. Marksteiner (Anm. 35). 


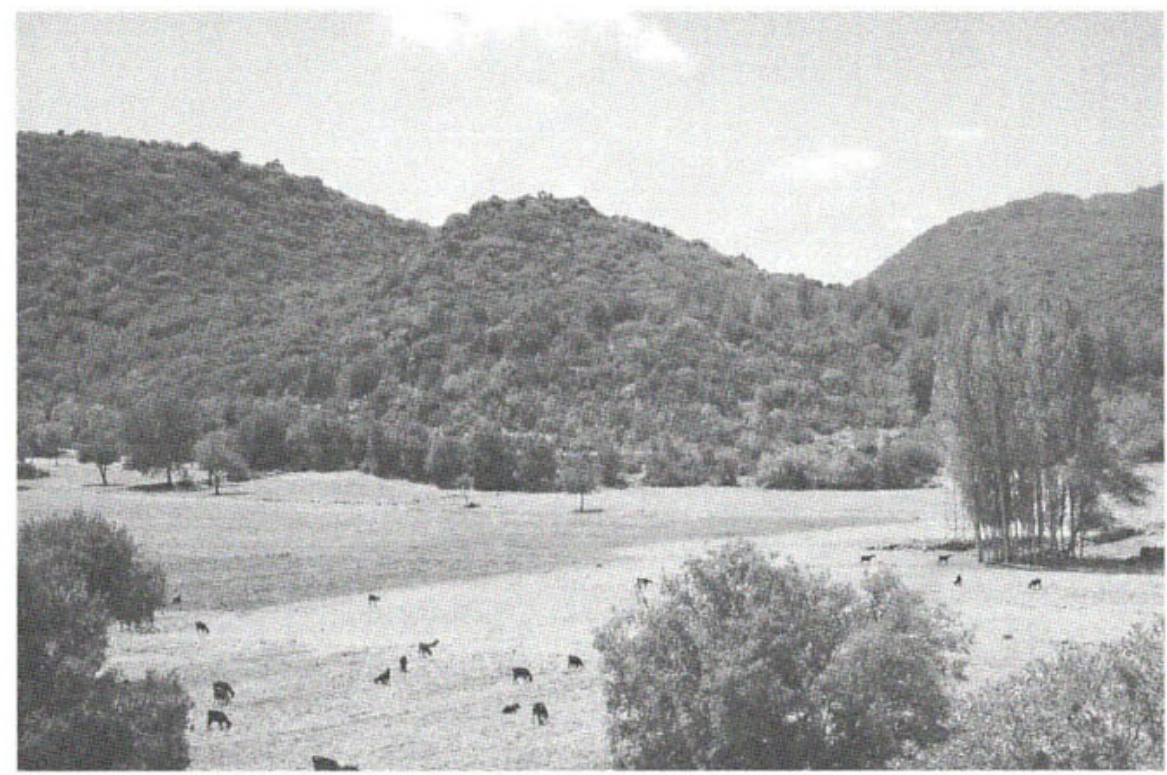

Abb. S: Blick auf klassisches Gehöft auf Bergkuppe.

Die bei klassischen Einzelgehöften regelmäßig anzutreffenden topographischen und architektonischen Kennzeichen sind noch einmal zusammenzufassen: Erstens bevorzugte man in der Dynastenzeit Sicherheitslagen, d.h. Standorte auf exponierten Hügelkuppen (Abb. 5) oder in markanten Spornlagen. Die Kontrolle des Vorfeldes und des zugehörigen Wirtschaftslandes sowie eine möglichst geeignete Verteidigungsposition waren die Hauptgründe für die erhöhten Standorte. Dies brachte gelegentlich den Nachteil einer größeren Entfernung von den Ackerflächen mit sich. Zweitens besitzen vorhellenistische Gehöfte in der Regel einen kompakten Grundriß. Die Außenmauern können eine nahezu geschlossene Befestigungslinie bilden, wobei die Mauerstärke $1 \mathrm{~m}$ nur selten unterschreitet, in vielen Fällen sogar deutlich darüber liegt. Drittens besitzen selbst großräumig angelegte Gehöfte oftmals nur einen einzigen Zugang, der zwar durch die Verwendung monolither Blöcke repräsentativ gestaltet sein kann, dessen Durchgangsweite aber in der Regel selten mehr als $1 \mathrm{~m}^{\text {beträgt }}{ }^{38}$. Alle topographischen und architektonischen Indizien zusammengenommen, bezeugen eine $\mathrm{z}$. T. ausgeprägte Wehrhaftigkeit klassischer Gehöfte, bilden mithin einen Beleg dafür, daß die Verhältnisse auf dem Land auch in klassischer Zeit noch einigermaßen unsicher waren.

Leider geben die bislang registrierten klassischen Baukomplexe keine Antwort auf die Frage, ob bzw. in welchem Verhältnis subsistenz- und/oder marktorien- 
tiert produziert wurde. Die hohe Bauqualität vieler Turmgehöfte spiegelt freilich einen beachtlichen Wohlstand der Hofbesitzer wider, der für Überschußproduktion spricht. In diesem Zusammenhang stellt sich die Frage nach der landwirtschaftlichen Palette in klassischer Zeit. Welche Bedeutung hatten beispielsweise Terrassenkulturen wie Oliven und Wein? Bislang ist nämlich noch nicht eindeutig zu beantworten, in welchem Umfang bereits in klassischer Zeit Terrassenwirtschaft betrieben wurde. Allerdings kann in diesem Zusammmenhang die Statistik einen Hinweis geben: Im gesamten Umland wurden rund 400 Preßanlagen gefunden, wobei 42 Einzelgehöfte unmittelbar mit solchen Einrichtungen verbunden sind. Aber nur fünf dieser Gehöfte sind möglicherweise dynastenzeitlich zu datieren, während das Gros der Gehöfte mit Preßanlagen in hellenistischer Zeit bzw. in der Kaiserzeit gebaut wurde. Dies ist wohl ein Indiz dafür, daß im Yavu-Bergland Oliven-/Weinproduktion in vorhellenistischer Zeit auf jeden Fall eine untergeordnete Rolle spielte, während Viehzucht und Weidebetrieb einen großen Stellenwert besaßen.

Dies bezeugen die mit archaischen und klassischen Anlagen verbundenen ummauerten Höfe, die in vielen Fällen einen verhältnismäßig großen Flächenanteil im Gehöftgefüge einnehmen und hauptsächlich dem Schutz des eigenen Vieh gedient haben dürften: Ein wohl ins 4. Jahrhundert v. Chr. zu datierendes Gehöft, das am Westrand des Territoriums oberhalb eines ins benachbarte Kasaba-Tal hinabführenden Paßweges errichtet wurde, ist mit einem ca. $20 \mathrm{~m} \times 20 \mathrm{~m}$ großen Mauerviereck ausgestattet (Abb. 6) ${ }^{39}$. Der Innenraum ist mit Felsen bestanden und es haben sich an keiner Stelle Reste von Binnenstrukturen erhalten. Eine Nutzung als Viehgehege, das außerdem in akuter Gefahr auch als befestigte Zuflucht für die Bewohner der benachbarten Gehöfte gedient haben könnte, erscheint evident. Wohl ebenfalls mit Weidewirtschaft sind relativ stark ummauerte Hofanlagen zu verbinden, die keinen Gebäudebestand oder nur kleine Einraumhäuser aufweisen und in Steilhanglage oder auf felsigen Hochflächen errichtet wurden. Bei diesen Anlagen handelt es sich wohl um externe Viehgehege, die in einigen Fällen mit einfachen Hirtenunterkünften ausgestattet und nur temporär von mit ihren Herden durchs Bergland ziehenden Hirten genutzt wurden ${ }^{40}$. Der in einigen Fällen bemerkenswerte Bauaufwand mit Mauerstärken über $1,40 \mathrm{~m}$ ist sicher ein Reflex des potentiell riskanten Hirtenalltags im lykischen Bergland.

Nach Auflösung der Dynastenherrschaften und der Einrichtung der Polis Kyaneai um die Mitte des 4. Jahrhunderts v. Chr. kommt es auf dem Land zu spürbaren Veränderungen. Dies läßt sich vor allem an der Zahl und Verteilung der bewirtschafteten Einzelgehöfte ablesen. Von hellenistischer Zeit bis in die Kaiserzeit werden rund 190 Gehöfte neu gebaut, darunter 88 Turmgehöfte. Da gemäß der Oberflächenkeramik 10 bis 12 der klassischen Turmgehöfte sowie

39 Verf., in: Lykische Studien 5 (2000) $72 \mathrm{f}$.

40 In der Regel findet sich in externen Viehgehegen nur sehr wenig bzw. überhaupt keine Keramik. 


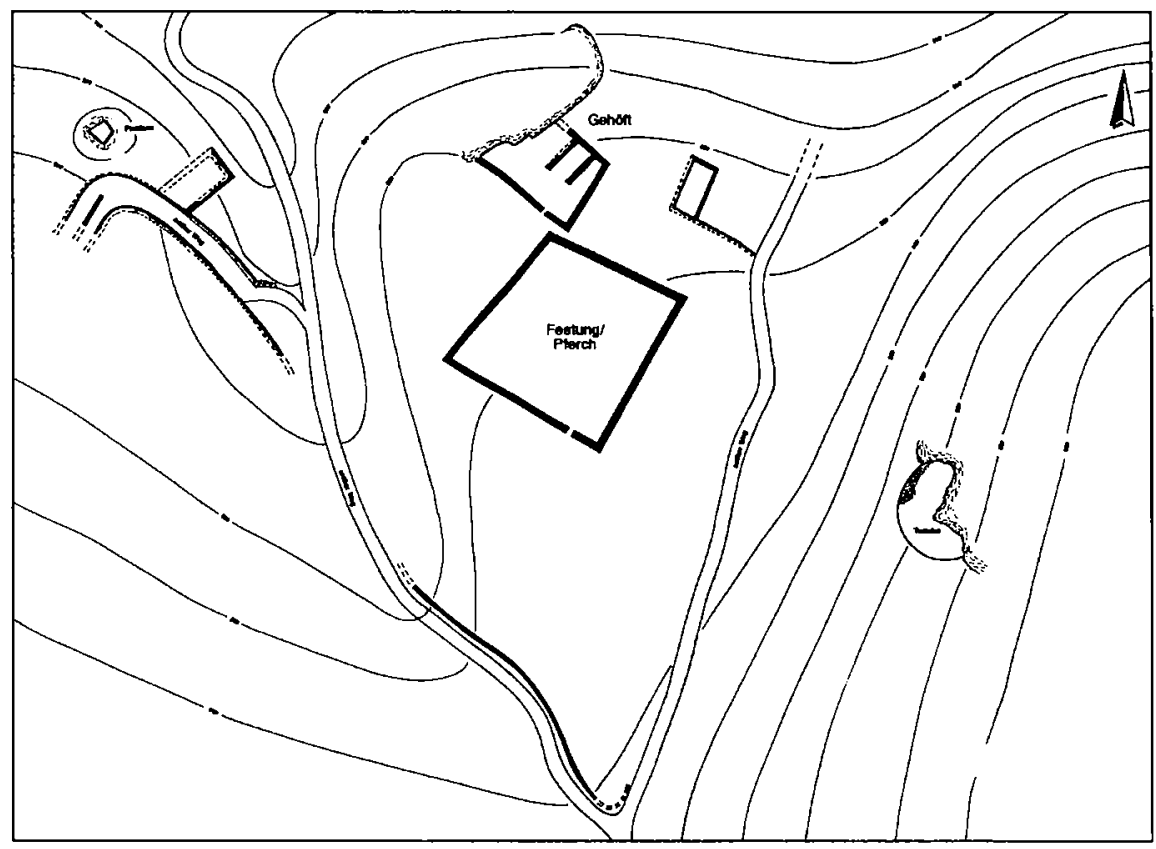

Abb. 6: Grundriß einer klassischen Geböftanlage mit befestigtem Viehgebege am Nordausgang der Abatl-Ebene.

15 Gehöfte ohne Turm weitergenutzt wurden, steigt die Zahl der bewirtschafteten Einzelgehöfte in diesem Zeitraum auf etwa 215 Anlagen an. Ob die Zunahme der Gehöfte linear oder sprunghaft verlief, ist ohne Feinchronologie kaum zu beantworten.

Das Gehöftenetz wird insgesamt engmaschiger, dabei verteilen sich die Einzelgehöfte im Vergleich zur klassischen Epoche gleichmäßiger übers Land (Abb. 5 auf S. $18 \mathrm{f}$.). Zwar bildet das Umland des Avşar Tepesi einschließlich der Kırandağı-Region auch nach Auflassung des Dynastenortes einen regionalen Siedlungsschwerpunkt. Seit hellenistischer Zeit entwickelt sich nun aber auch im Umfeld der neuen Komenzentren Korba, Trysa und Hoyran eine dichtere ländliche Besiedlung; auch im Umland des neuen Poliszentrums Kyaneai steigt die Zahl der Einzelgehöfte merklich an, allerdings insgesamt weniger auffällig als um die Komenzentren. Ein besonderes Phänomen ist die Häufung von Turmgehöften im Bereich kleiner Ackerebenen: Beispielsweise werden im Nordwesten des Territoriums im Umland von Korba acht Turmgehöfte in $z$. T. sehr enger Nachbarschaft errichtet, und westlich des Avşar Tepesi sowie nördlich des Çeştepe steigt die Zahl der Turmgehöfte gleichfalls an. Diese Teilgebiete öffnen sich sämtlich nach Südosten und sind mit einem unruhigen, aber keineswegs schroffen Oberflächenrelief 
ausgestattet, in das kleine Fruchtebenen eingestreut sind. Ein solches Landschaftsbild bietet für eine gemischte Landwirtschaft vorzügliche Bedingungen: Ackerund Terrassenbau sowie - in kleinerem Maßstab als noch in klassischer Zeit Viehwirtschaft dürften Existenz und Wohlstand der Gutsbesitzer gesichert haben. $\mathrm{Da}$ die Mehrzahl dieser in enger Nachbarschaft errichteten Turmgehöfte nach dem Keramikbefund wohl zeitgleich in Nutzung standen, wüßte man gerne, auf welche Weise Besitz- und Wirtschaftsgefüge in solchen ,Ballungsräumen' organisiert waren.

Für die stattliche Zahl agrarischer Siedlungsplätze im Nord- und Südwesten der Region scheint aber auch die verkehrsgeographische Lage innerhalb des YavuBerglandes ausschlaggebend gewesen sein. Die meisten der neu gebauten Gehöfte liegen beiderseits antiker Überlandwege. Das heißt, ein möglichst bequemer Zugang zu den lokalen und regionalen Absatzmärkten dürfte bei der Wahl des Bauplatzes ein mitentscheidendes Kriterium gewesen sein. Der gewachsene Stellenwert der Landwirtschaft läßt sich aber nicht nur an der größeren Zahl der Einzelgehöfte ablesen. Wie in vorhellenistischer Zeit können auch Topographie und Architektur Aufschlüsse über die Lebensumstände auf dem Land geben. Es ist wohl kein Zufall, daß hellenistische und kaiserzeitliche Gehöfte am Rand der Fruchtebenen gebaut werden. Die Nähe zum eigenen Land und die möglichst zweckmäßige Bewältigung des bäuerlichen Alltags werden offenbar seit hellenistischer Zeit zu wesentlichen Standortkriterien; Plätze, die eine natürliche Schutzposition bilden und in der Dynastenzeit noch bevorzugt ausgewählt worden wären, verlieren an Attraktivität.

Davon ist freilich nicht generell abzuleiten, daß dem Aspekt der Wehrhaftigkeit nun überhaupt keine Bedeutung mehr beigemessen wurde. Hier ist zu differenzieren: Während die turmlosen Gehöfte in der Tat weniger kompakt angelegt werden und nur selten die für archaisch-klassische Einzelgehöfte charakteristischen starken Mauern besitzen, sind die hellenistischen Turmhäuser ebenso wehrhaft-solide gebaut wie ihre klassischen Vorläufer; ein klarer Anhalt für den Defensivcharakter der hellenistischen Turmhäuser ist in der Fensterlosigkeit des Erdgeschosses und in der Höherlegung der Turmtür zu erkennen. Allerdings ist die Gesamtanlage hellenistischer Turmgehöfte im Vergleich zu klassischen Anlagen in der Regel weniger kompakt (Abb. 7): Die Nebengebäude sind nicht so fest in das Gehöftgefüge eingebunden, und die nach außen gerichteten Gebäude- und Hofmauern, die bei klassischen Turmgehöften oftmals ebenso massiv wie die Mauern des turmartigen Kernbaus gebaut sind, sind bei hellenistischen Gehöften in der Regel weniger massiv; ummauerte Höfe können sogar ganz fehlen. Die gehobene Bauqualität der meisten hellenistischen Turmgehöfte scheint in größerem Maße als bei klassischen Gehöften der Selbstdarstellung der Hofherren gedient zu haben. Dies zeigt sich auch an der Übernahme moderner Bau- und Steinbearbeitungstechniken aus dem griechischen Bereich - beispielsweise werden im Gehöftbau seit hellenistischer Zeit in zunehmendem Maße Quader sowie regelmäßig versetzte Binderblöcke verwendet -, wodurch man demonstrierte, daß man auch auf dem Land architektonisch auf der Höhe der Zeit war (Abb. 8). 


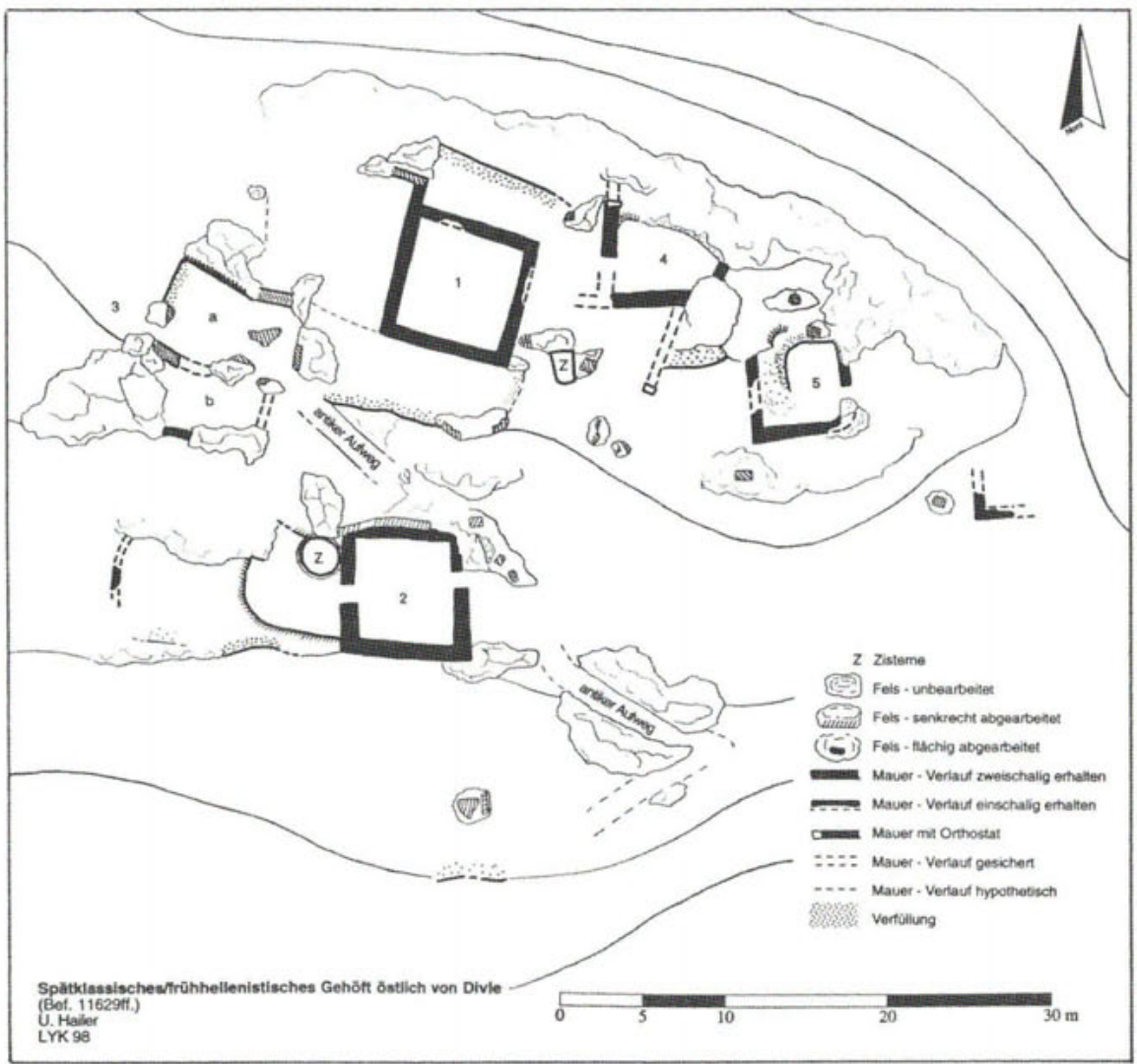

Abb. 7: Grundriß eines hellenistischen Gehöftes östlich Divle.

In der Zusammenschau bezeugen die seit spätklassischer/frühhellenistischer Zeit zunehmende Zahl an Einzelgehöften, die regelmäßigere Verteilung der Bauernhöfe in der Chora, die vor allem nach wirtschaftlich-ökonomischen Kriterien ausgewählten Gehöftstandorte sowie die insgesamt weniger fortifikatorisch ausgeprägte Gesamtanlage der hellenistischen Gehöfte einen offenbar nach Einrichtung der Polis einsetzenden Entwicklungssprung im ländlichen Sektor, der offensichtlich auch die ,Agrartechnologie‘ einschloß: Oliven- und Weinanbau gewinnen im Zuge der Aufsiedlung und wirtschaftlichen Erschließung der Chora zunehmend an Bedeutung. Wie angedeutet, zeigt sich dies vor allem an der hellenistischen und kaiserzeitlichen Datierung der meisten mit Preßanlagen verbundenen Gehöfte. Ein weiteres Indiz für die seit dem 4. Jahrhundert v. Chr. stark gewachsene Bedeutung von Olive und/oder Wein bilden die im Umfeld hellenistischer und kaiserzeitlicher Gehöfte vielfach registrierten Terrassenkomplexe, wie 


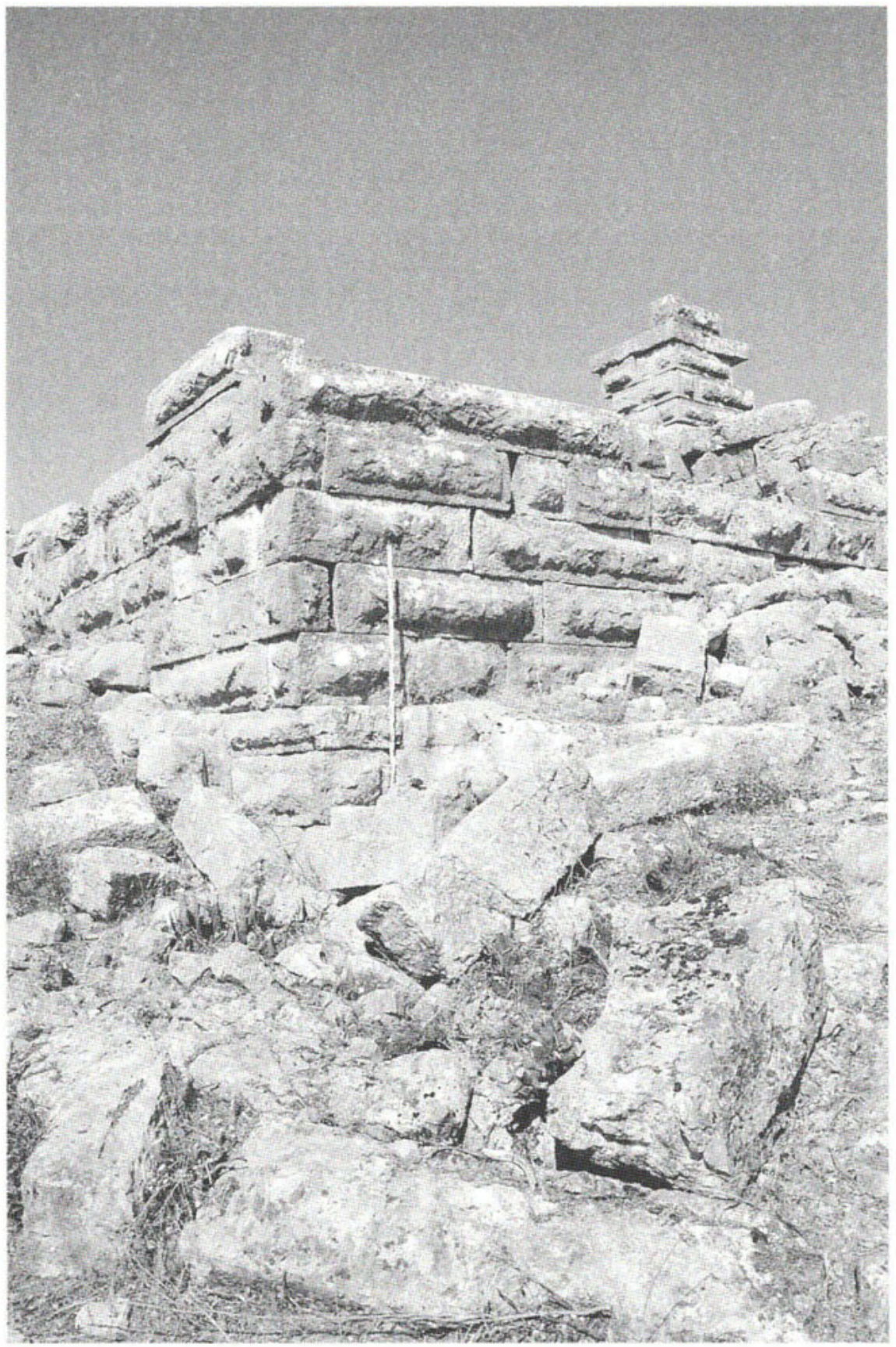

Abb. 8: Maueransicht des hellenistischen Turmgehöftes bei Gelemen. 
sie bei vorhellenistischen Gehöften nur selten zu finden und dort möglicherweise einer späteren Nutzungsphase zuzuschreiben sind. Mit einer entwickelten marktoder sogar exportorientierten Wein- und Ölproduktion ist im Yavu-Bergland erst seit der Einrichtung der Polis Kyaneai zu rechnen

Die seit hellenistischer Zeit ansteigende Zahl an Einzelgehöften spiegelt gewiß eine zahlreicher werdende ländliche Bevölkerung wider. Allerdings gestaltet sich eine Berechnung der in Einzelgehöften lebenden Bevölkerung auf Grundlage allein des archäologischen Befundes schwierig. Die Zahl der Bewohner eines Bauernhofs ist nämlich im Einzelfall nur dann zu schätzen, wenn Anzahl und Nutzung der einzelnen Gebäude und Räume einer Gehöftanlage bestimmt werden können. Solange dies nicht der Fall ist, sind entsprechende Berechnungsversuche sehr vorsichtig zu bewerten. Zwar ist davon auszugehen, daß in einem vielräumigen Gehöft mit großer Grundfläche mehr Personen wohnten als in einer kleinen Bauernstelle. Aber auch ein kleiner Bauernhof konnte einer durchaus stattlichen Zahl von Bewohnern ausreichend Platz bieten, wie das Beispiel eines nördlich von Tüse liegenden hellenistisch-kaiserzeitlichen Gehöfts zeigt. Die Anlage setzt sich aus einem einräumigen Gebäude mit einer Nettonutzfläche von ca. 20 Quadratmetern und einem ca $10 \mathrm{~m} \times 8 \mathrm{~m}$ großen Hof mit einem eingebauten kleinen Raum. Ein nur wenige Meter von dem Gehöft aufgestellter kaiserzeitlicher Sarkophag nennt uns diejenigen Gehöftbewohner, die das Recht haben, in der Grablege bestattet zu werden ${ }^{41}$ : der Besitzer und seine Ehefrau sowie die Söhne, Enkel und Sklaven. Das bedeutet, zwischen sechs und zehn Personen dürften zeitweise diese relativ kleine, aus nur zwei Gebäuden mit geringer Grundfläche bestehende $\mathrm{Ge}$ höftanlage bewohnt haben. Nimmt man dieses Kleingehöft zum Gradmesser, stellt sich die Frage, wieviele Personen in einem der großen Turmgehöfte der Region gelebt und gearbeitet haben (Abb. 9). Möchte man die aus der wachsenden Zahl der Gehöfte ersichtliche demographische Entwicklung numerisch fassen, und legt - unabhängig von der tatsächlich festgestellten architektonischen Vielfalt und Größe der Gehöfte im Yavu-Bergland - eine zurückhaltend geschätzte Bewohnerzahl von durchschnittlich sechs Personen je Gehöft zugrunde, lebten in der Dynastenzeit wohl mindestens 800-900 Menschen in Bauernhöfen. Bis in die Kaiserzeit steigt die Zahl auf ca. 1300 Personen an. Fragt man nun nach den Ursachen für diesen Bevölkerungsanstieg, so ist die mit der fortschreitenden ErschlieBung der Chora verbundene, seit hellenistischer Zeit, d. h. seit Einrichtung der Polis Kyaneai offensichtlich stetig wachsende Bedeutung einer marktorientierten Landwirtschaft an erster Stelle zu nennen.

${ }^{41}$ M. Zimmermann, in: Lykische Studien 2, $52 \mathrm{f}$. 


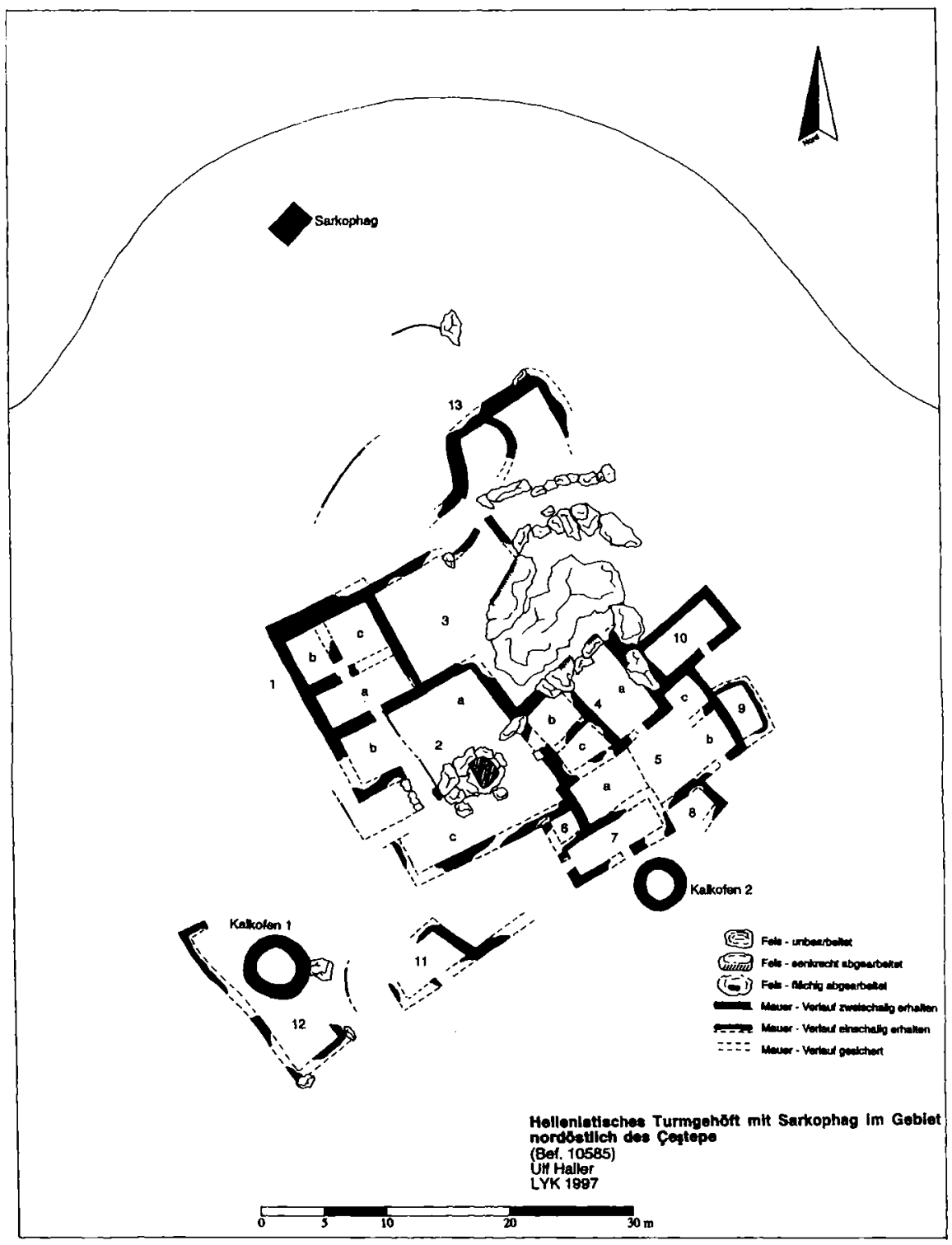

Abb. 9: Grundriß eines hellenistischen Turmgehöftes nordöstlich Çeştepe. 


\section{Kleine ländliche Siedlungen}

Neben Einzelgehöften bestimmen kleine ländliche Siedlungen das Bild der Kulturlandschaft der Polis Kyaneai. Auf dem bisher systematisch erforschten Areal im Yavu-Bergland wurden 69 solcher Siedlungen entdeckt, die unterschiedlichen Epochen angehören ${ }^{42}$. Es handelt sich dabei um kleinere Ansiedlungen ohne Zentralortfunktion. Als Terminus für diesen Siedlungstypus kann man das griechische chorion benutzen, auch wenn dieser Begriff erst seit der frühbyzantinischen Zeit als Bezeichnung für kleine Ortschaften und Weiler bezeugt ist ${ }^{43}$.

Als Voraussetzung dafür, einen Ort mit verstreut liegenden Wohnbauten als ländliche Siedlung zu bezeichnen, gilt zunächst eine Zahl von wenigstens drei Wohnhäusern ${ }^{44}$. Dabei darf der Abstand zwischen benachbarten Wohnbauten die sogenannte Rufweite nicht überschreiten ${ }^{45}$. Dieses Kriterium ist angesichts der hohen Siedlungsdichte auf dem Gebiet von Kyaneai jedoch nicht anwendbar. Vielmehr muß der jeweilige, von Siedlungsstruktur und Landschaftsrelief bestimmte Gesamteindruck über die Definition der Siedlungsform entscheiden. In aller Regel ist dies noch unproblematisch. Schwierigkeiten resultieren aber z.B. daraus, daß bei manchen Anlagen sehr schwierig zu entscheiden ist, ob es sich um kleine Kompaktsiedlungen oder um große Gehöftanlagen handelt. Ferner gibt es Fälle, in denen eine Siedlung anfangs nur aus einem Einzelgehöft bestanden hat und erst später erweitert worden ist.

Weitere Probleme liegen vor allem in der Datierung der Befunde, da bisher keine Ausgrabungen in solchen Siedlungen durchgeführt werden konnten. Deshalb muß man sich zunächst mit den vorläufigen, jedoch durch Analogien einigermaßen gesicherten Datierungskriterien der Mauertechniken und der Oberflächenfunde, wie Keramik und sonstiger Kleinfunde sowie der topographischen

42 Zur Verteilung dieser kleinen Siedlungen auf dem Territorium s. Faltplan 5 (Stand 1997), in: Lykische Studien 5 (2000) und Faltplan 2 in Lykische Studien 6 (2003). Sie sind auf der Karte grau markiert und mit römischen Ziffern versehen.

43 G. Anrich (Hagios Nikolaos. Der heilige Nikolaos in der griechischen Kirche Bd. II 1917 $539 \mathrm{f}$.) bemerkt, ,daß chorion als zusammengehörige Häusergruppe zu verstehen sei und kome umfaßte die kleinere Einheit chorion'. Vgl. dazu zuletzt: H. Blum, Die Vita Nicolai Sionitai, (1997) Kap. I 41, 58-61, 66, 70, 79 und S. 94, 110, 123; Blum, Lykia 1 (1994) 52-67. G. Zur chorion als Untergliederung von kome in Oinoanda bzw. in Pinara und Sidyma s. W. Wörrle, Stadt und Fest im kaiserzeitlichen Kleinasien (1988) $139 \mathrm{f} \mathrm{m.} \mathrm{Anm.} \mathrm{354.} \mathrm{Für} \mathrm{die} \mathrm{Zu-}$ sammenstellung der Belege und Literatur sowie für den Gebrauch von kome und chorion s. Chr. Scbuler, Ländliche Siedlungen und Gemeinden im hellenistischen und römischen Kleinasien (1998) 49-53, insbesondere 52f. m. Anm. 205-211. Seiner Meinung nach „muß offen blciben, inwieweit Kome und chorion verschiedene Organisationsgrade andeuten. Festzuhalten ist, daß chorion als Weiler vor dem Ende der Spätantike nicht in den kleinasiatischen Inschriften begegnet, daß aber andererseits die Zuordnung kleinerer Ortschaften zu Dorfgemeinden bereits in hellenistischer Zeit zweifelsfrei belegt ist" .

${ }^{44}$ Vgl. dazu Chr. Schuler, a.O. 14 m. Anm. 30-32.

45 Diese wird in der modernen Siedlungsgeographie mit etwa $150 \mathrm{~m}$ angesetzt. Auch Diodor XVI 60, 2 definiert den Abstand, bei dem man von getrennten Siedlungen ausgehen kann, mit ca. $150 \mathrm{~m}$. Vgl. Chr. Schuler, a.O. 27 m. Anm. 59, 60 . 
Lage, zufriedengeben. Die in der Regel schlichte Mauertechnik läßt sich nur aufgrund der breiten statistischen Basis für eine grobe Chronologie auswerten. Die aufgelesene Oberflächenkeramik enthält zwar stets nur eine begrenzte Zahl signifikanter Fragmente, doch trägt sie wesentlich dazu bei, das lückenhafte Bild, das wir aus den Datierungen der Mauertechniken und aus der Topographie gewinnen, zu ergänzen.

\begin{tabular}{lc}
\hline & Zahl der Siedlungen \\
\hline mit Keramikfunden & 66 \\
ohne Keramikfunde & 3 \\
mit datierbarer Keramik & 61 \\
\hline
\end{tabular}

Die kleinen ländlichen Siedlungen in unserem Forschungsgebiet lassen sich grob nach zwei Typen klassifizieren: Konglomeratsiedlungen und Streusiedlungen. Konglomeratsiedlungen breiten sich in zusammenhängender Bebauung auf der verteidigungsfähigen, felsigen Kuppe eines Hügels und teilweise auch an seinen terrassierten Hängen aus. Eine Streusiedlung dagegen besteht aus vereinzelten Gebäuden, die sich oft lose um einen älteren Kernbau - meist ein Turmgehöft herum gruppieren. Bei den späten Siedlungen dieses Typs liegen an der Peripherie oft ein bis drei kleine Kirchen. Am Fuß der Siedlungshänge befindet sich fast immer eine ackerbaufähige Ebene ${ }^{46}$.

Diese beiden Typen lassen sich in eine chronologische Reihenfolge bringen. Siedlungen, die der klassischen und hellenistischen Zeit angehören, sind meist dem ersten Typus zuzuordnen. Ab der hellenistischen Zeit beobachtet man freilich, daß die Hügelkuppen allmählich verlassen werden. Die Gebäudereste liegen nun meist an den Hängen, bisweilen auch am Fuß eines Hügels, während in der spätantik-byzantinischen Zeit die Siedlungen fast immer auf einer leicht erhöhten Terrasse am Rand der Ebenen gegründet werden ${ }^{47}$.

Kleine, dorfähnliche Siedlungen sind erst ab der klassischen Zeit vereinzelt auf dem Territorium von Kyaneai anzutreffen. Das Siedlungsbild dieser Epoche ist jedoch noch nicht von ihnen, sondern von Einzelgehöften geprägt. Es wurden im bisher begangenen Forschungsgebiet lediglich sieben ländliche Siedlungen festgestellt, für die eine klassische Nutzungsphase bezeugt oder wahrscheinlich ist.

Deren Siedlungsbild ist von einer exponierten topographischen Lage und einer kompakten Struktur geprägt. Es ergibt sich ein burgartiger Eindruck. Die obersten Raumeinheiten sind sorgfältig aus dem anstehenden Fels gehauen. Die Siedlungen verfügen in der Regel über fünf bis sechs Häuser mit einem Siedlungsareal

46 Zur Siedlungstypologie s. A. Thomsen in: Lykische Studien 1 (1993) $39 \mathrm{ff}$.; ders. in: Lykische Studien 2 (1995) 57 ff.; Verf. in: Lykische Studien 4 (1998) 55.

47 Als Ausnahme von dieser Typologie gibt es auf dem Territorium von Kyaneai freilich drei späte Siedlungen, die einen teilweise kompakten Charakter zeigen und damit zwischen beiden Typen schwanken. 
von durchschnittlich einem halben Hektar. In der hellenistisch-kaiserzeitlichen Epoche sind sie aber oft erweitert bzw. überbaut worden.

Die Probleme bei der Analyse dieser Siedlungspalimpseste zeigt ein Fundort nördlich des antiken Komenzentrums Hoyran. Er befindet sich auf einem Hügel direkt oberhalb des kleinen Dorfes Divle (Abb. 10). Die Gebäudereste liegen auf der Hügelkuppe und verstreut an seinen südlichen und südwestlichen Hängen bis an den Fuß des Hügels. Die Siedlung besteht aus insgesamt ca.15 Gebäuderesten, drei Preßanlagen, acht Zisternen und einer spektakulären Nekropole ${ }^{48}$.

Auf der höchsten Stelle des Hügels liegt ein Komplex mit zahlreichen Felsräumen (Abb. 11), einer rechteckigen, großen Zisterne, kleinen Becken und Treppen. Seine Lage und Kompaktheit deuten auf einen gewissen Wehrcharakter hin. Sehr viele Steinbettungen sind auf den Felswänden zur Aufnahme quaderartiger Blöcke ausgearbeitet und weisen darauf hin, daß hier ehemals aufgehendes Mauerwerk stand. Es muß jedoch angesichts des heutigen Zustandes offenbleiben, ob die Wände vollständig aus Steinmauern oder $z$. T. auch aus Fachwerk errichtet waren, da im umliegenden Areal nur eine geringe Menge von Steinmaterial als Versturz vorhanden ist.

Obwohl nicht viele in die klassische Zeit datierbare Gebäudereste nachzuweisen sind - der Großteil gehört in die hellenistisch-kaiserzeitliche Epoche -, hat man zwei weitere Anhaltspunkte für die frühe Besiedlungsphase: erstens die recht zahlreichen in klassische Zeit datierbaren Keramikfragmente mit Schwarzfirnis ${ }^{49}$ und zweitens die Nekropole der Siedlung ${ }^{50}$. Letztere besteht aus 23 Felsgräbern, die in die westlichen und östlichen Wände eines Felskessels gehauen sind und zweifellos in die klassische Zeit gehören; sie geben als Familiengräber auch einen Anhaltspunkt für die Bevölkerungszahl der Siedlung.

Der Kessel muß durch den Einsturz einer natürlichen unterirdischen Höhle enstanden sein. Er hat eine Breite von $35 \mathrm{~m}$ (im Süden) bis zu $90 \mathrm{~m}$ (im Norden), eine Länge von $100 \mathrm{~m}$ und ist ca. $50 \mathrm{~m}$ tief. (Abb. 10, 12) $)^{51}$. Die Gräber liegen in unter-

48 Eine ausführlichere Abhandlung dieser Siedlung mit ihrer Nekropole ist im Rahmen des Dissertationsprojektes der Verfasserin in Arbeit.

${ }^{49}$ Zwei archaische (F 10197, F 10200) und zwei archaisch/klassische Scherben (F 8939, F 10188) lassen angesichts des heutigen Forschungsstandes ohne Sondage keine nähere Aussage darüber zu, ob und inwieweit hier ab der archaischen Zeit mit einer Ansiedlung zu rechnen ist. Näheres zu den betreffenden archaischen Fragmenten s. $B$. Rückert in: Lykische Studien 8 (in Vorbereitung).

50 Ein ähnlicher Siedlungsplatz (Siedlung 1) mit einer Felsgräber-Nekropole, der in den von Martin Zimmermann 1999 durchgeführten Feldforschungen im Umland von Teimiusa entdeckt wurde, befindet sich am Rand der Tirmisin-Ebene. Zu einem Vorbericht der betreffenden Kampagne s. M. Zimmermann in: AW 31 (2000) 333-342. Außer den Felsgräbern ist im näheren Umkreis keine in die klassische Zeit datierbare Bausubstanz nachweisbar.

51 Solche Dolinen kommen sonst im zentralanatolischen Hochland auf der Kalkplatte ,Obruk Yayla (Hochebene) 'vor (auch im türkischen Obruk genannt). Die Formen solcher Dolinen ähneln einander sehr. Einige Dutzend Dolinen, die sich in der Nähe des Ortes Kızören, etwa $40 \mathrm{~km}$ südlich des Tuz Gölü befinden, haben einen Durchmesser zwischen 50 und $200 \mathrm{~m}$ und eine Tiefe von 50 bis $120 \mathrm{~m}$. Einige sind mit Wasser gefüllt, welche vermutlich durch unterirdische Karstquellen gespeist werden. Siehe dazu N. Güldal, Geomorphologie 


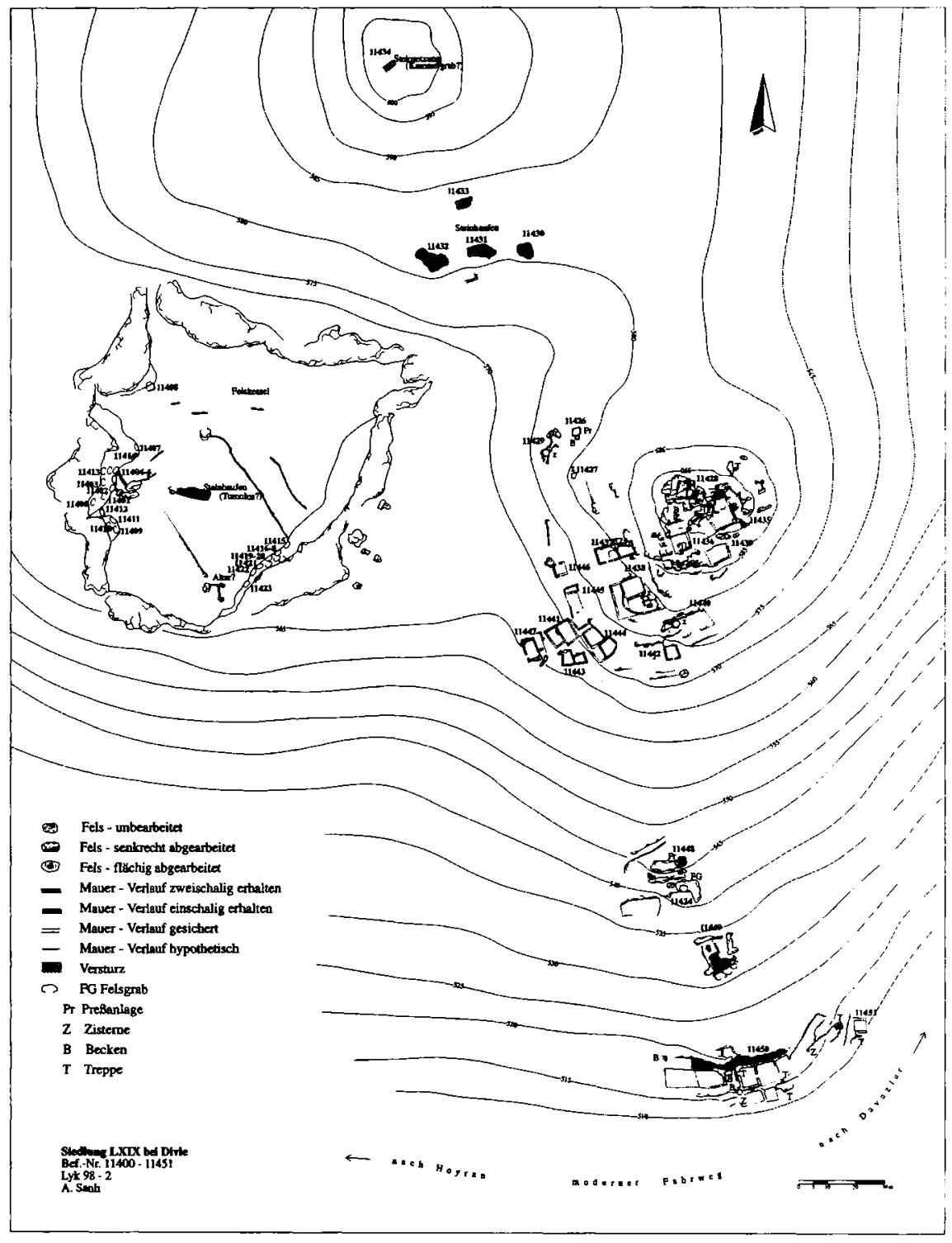

Abb. 10: Plan von Siedlung LXIX bei Divle. 


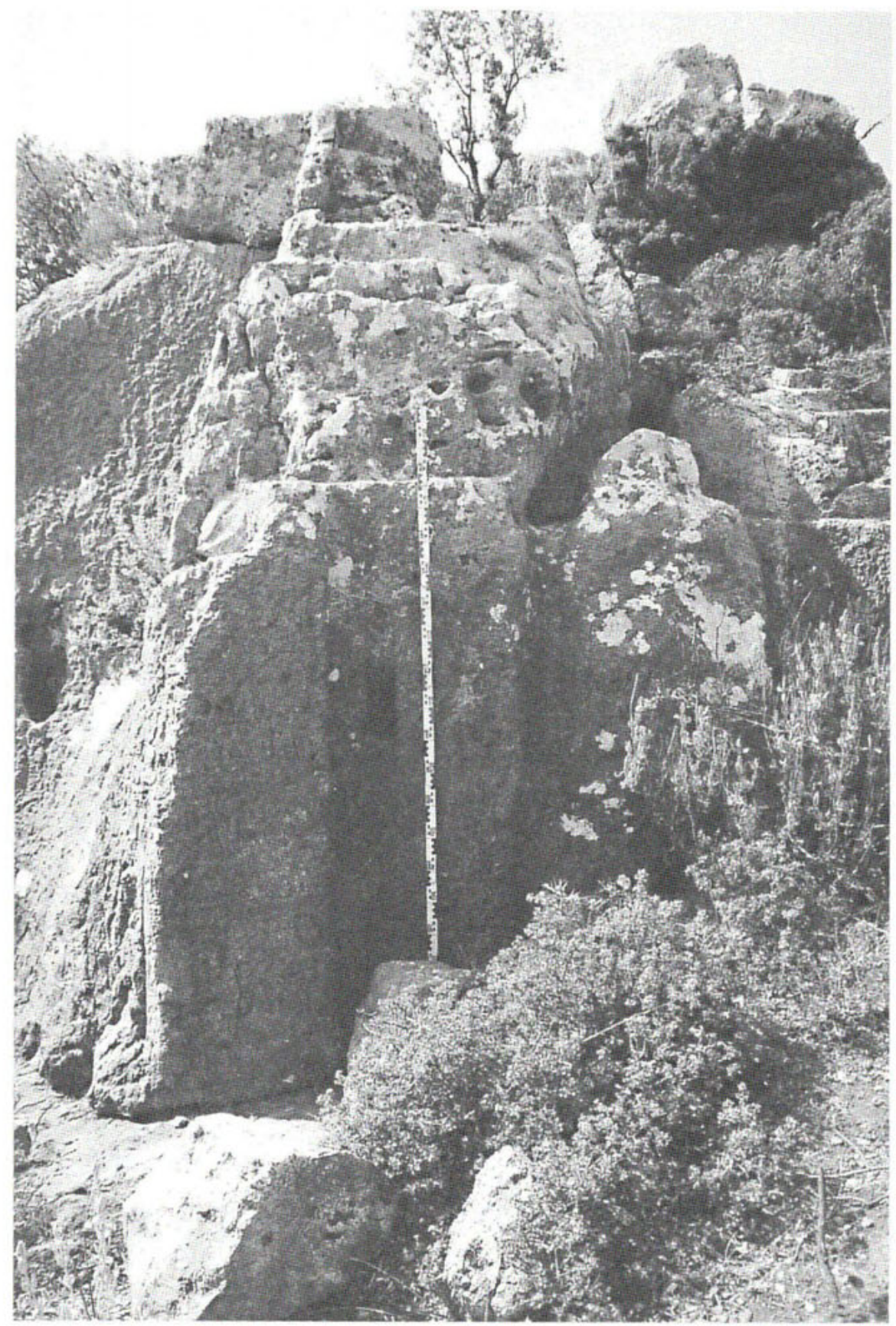

Abb. 11: Felskomplex in Siedlung LXIX bei Divle. 


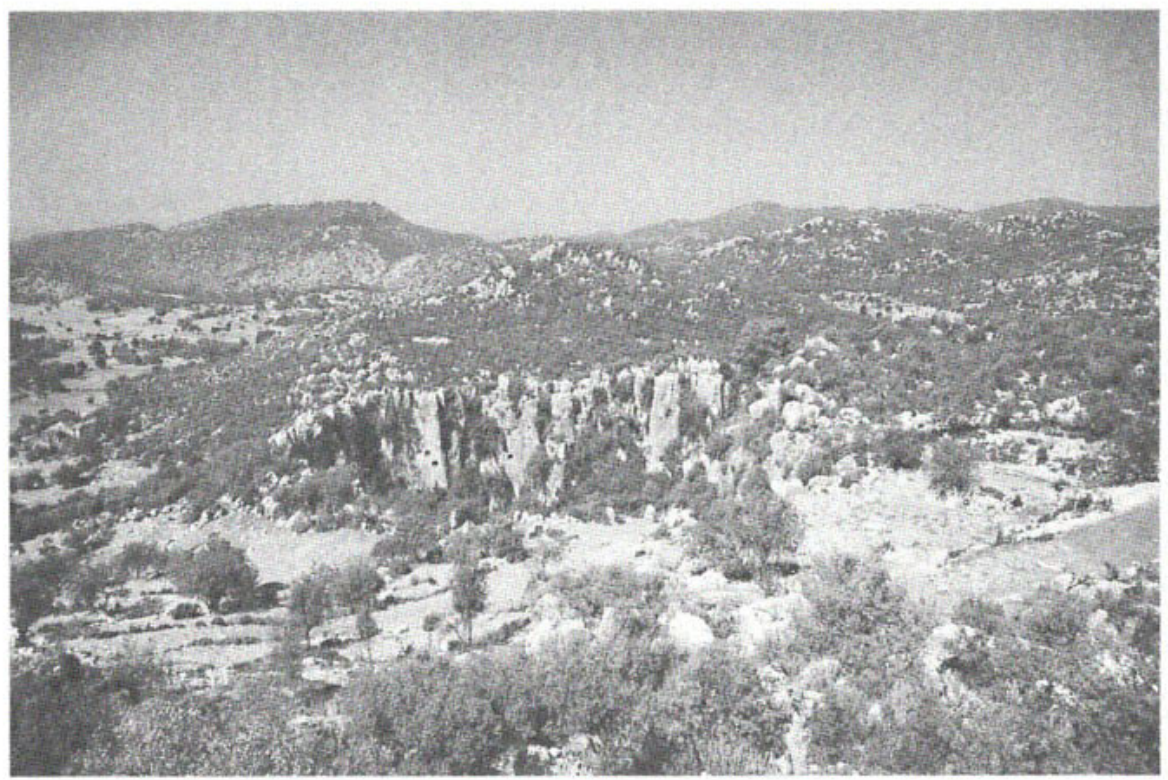

Abb. 12: Felskessel bei Divle.

schiedlicher Höhe, und bis auf eines sind alle als einfache, viereckige Felslöcher gestaltet. Nur ein Grab ist als Felsfassadengrab gestaltet, welches Holzarchitektur nachahmt (Abb. 13). Weil eine genaue zeitliche Einordnung derartiger Monumente beim heutigen Forschungsstand nicht möglich ist, kann man die lykischen Felsfassadengräber lediglich generell in die vorhellenistische Zeit datieren ${ }^{52}$. Die

der Türkei (1979) $61 \mathrm{ff}$. Abb. 8. Die Entstehungszeit dieser Dolinen im zentralanatolischen Hochland liegt ihm zufolge wahrscheinlich im Pleistozän.

52 Hinsichtlich der genaueren Datierung der Felsfassadengräber ohne Reliefs und Inschriften ist auch die Arbeit von Z. Kuban über die limyräischen Felsgräber abzuwarten: Z. Kuban in: ÖJh 66 (1997) Beibl. 348 ff. Eine zeitliche Einordnung der Felsfassadengräber mit Reliefs ergibt meistens die erste Hälfte des 4. Jahrhunderts v. Chr. Für die einfachen Felshöhlengräber bildet dieses Verfahren dagegen ein problematisches Unterfangen. Österreichische Reisende zählten die einfachen schmucklosen Grabhöhlen Pinaras an der steilen Felswand zu den ältesten Gräbern Lykiens: O. Benndorf, G. Niemann, Reisen im südwestlichen Kleinasien, I. Reisen in Lykien und Karien (1884) 48, 96. Es herrscht jedoch in der modernen Forschung die Meinung, daß solche einfachen Grabhöhlen nicht zwangsläufig am Anfang der Entwicklungsreihe lykischer Gräber standen: J. Borchhardt, Myra. Eine lykische Metropole in antiker und byzantinischer Zeit in: IstForsch 30 (1975) 98 Anm. 17; Ch. Bruns-Özgan, Lykische Grabreliefs des 5. und 4. Jahrhunderts v. Chr., IstMitt, Beih. 33 (1987) 92. Andererseits gibt es keine schlagkräftigen Argumente, um jene Überlegung, diese Gräber an den Anfang der lykischen Felsgräber zu setzen, gänzlich auszuschließen. In der altlykischen Siedlung Hızırhı/Telebehi - vermutlich die Vorgängersiedlung von Telmessos - bei Fethiye befinden sich neben den Tumuli und Pfeilergräbern über 100 Felshöhiengräber, während dort nur drei 


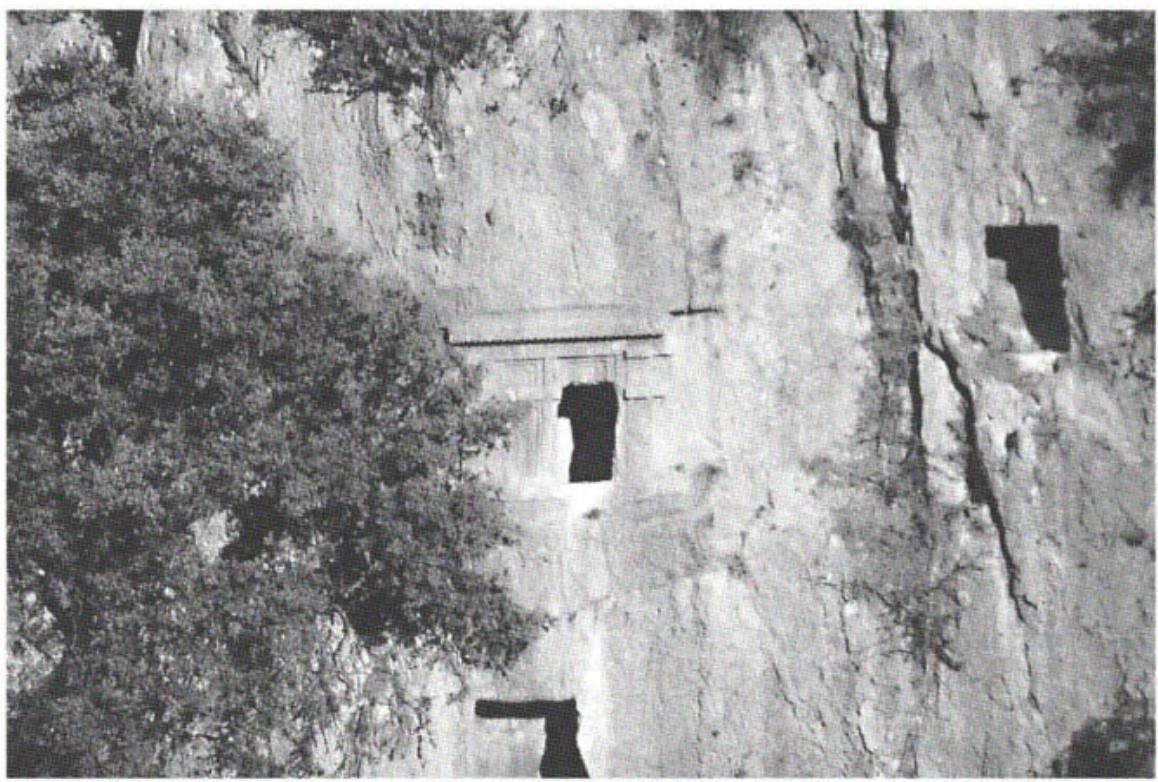

Abb. 13: Felsfassadengrab von Divle.

Öffnung eines der einfachen Grablöcher ist mit quaderartigen Blöcken und Mörtel vermauert. Dies weist darauf hin, daß es in späterer Zeit weiterbenutzt worden ist.

Die Oberflächenkeramik, die bis in die spätantike Zeit reicht, und die Gebäudereste am Westhang des Siedlungsareals zeigen, daß die Siedlung lange bewohnt war. Das Fehlen einer Kirche, byzantinischen Mauerwerks und byzantinischer Keramik indes beweist, daß sie vor der letztgenannten Zeit verlassen worden ist bzw. wohl allmählich an den Rand der unterhalb liegenden Ebene verlegt wurde.

Felsfassadengräber zu finden sind. Da die Siedlung vermutlich Ende des 5. Jahrhunderts v. Chr. oder in den beiden ersten Jahrzehnten des 4. Jahrhunderts aufgelassen wurde, bildet dies einen Datierungsanhalt für die Felshöhlengräber. Zur Siedlung von Hızırlık näheres s. bei K. Buschmann, Hızırlık bei Fethiye: Das lykische Telebehi in: X. Araştırma Sonuçları Toplantısı (1993) 429-437. Ein anderes Indiz für die frühe Entstehungszeit der einfachen Grablöcher als Felsfassadengräber ist die prominente Lage eines solchen Grabes zusammen mit frühen Pfeilergräbern auf der Agora des Avşar Tepesi, während sich zwei Felsfassadengräber in peripheren Lagen der jeweiligen Nekropole finden. Zu bemerken ist auch die Situation in Kyaneai: Während einige Felshöhlengräber direkt unterhalb der lykischen Akropolis (vergleichbar mit Pinara) liegen, finden sich die Felsfassadengräber weit entfernt vom Sedlungsplatz, in der Südostnekropole, so daß sie vermutlich später gefertigt worden sind. $\mathrm{Zu}$ den Felsgräbern auf dem Avşar Tepesi s. A. Thomsen, Die lykische Dynastensiedlung auf dem Avşar Tepesi (zitiert auf S. 13 Anm. 24) $176 \mathrm{ff}$. und $360 \mathrm{ff}$. Die Informationen über $\mathrm{H}_{1}$ zurlık/Telmessos und Kyaneai verdanke ich W. Tietz, der diese Überlegungen insbesondere über Felsgräber von Hizırlık ausführlicher behandelt hat: W. Tietz, Der Golf von Fethiye (Antiquitas R. 1, Bd. 50) (Bonn 2003) 81-85. 
Dies kann man recht sicher feststellen, weil dort eine byzantinische Siedlung (LXX) mit Kirche gefunden wurde ${ }^{53}$.

Probleme, verschiedene Siedlungsepochen zu unterscheiden, ergeben sich insbesondere bei der Differenzierung zwischen hellenistischen und kaiserzeitlichen Siedlungsstrukturen, da sich die einfachen Häuser aus der hellenistischen Zeit kaum von jenen der Kaiserzeit abheben. Die von der Erdoberfläche aufgelesene Keramik bietet in den meisten Fällen überwiegend kaiserzeitliche und spätantike Fragmente. Daher ist nicht auszuschließen, daß dort, wo einige hellenistische Scherben gefunden wurden, bisweilen nur ein oder zwei Einzelgehöfte existierten, während ab der Kaiserzeit um diese hellenistischen Gehöfte herum weitere Häuser gebaut worden sind.

Festzuhalten ist auf alle Fälle eine starke Zunahme der Siedlungen ab der Spätantike. 58 Siedlungen mit einer in diese Zeit datierbaren Nutzungsphase wurden registiriert.

Erst ab der Kaiserzeit vermitteln uns zudem die in den Siedlungen vorgefundenen Überreste das Bild einer lebhaften landwirtschaflichen Tätigkeit. Sie verfügen über zahlreiche Preßanlagen, welche in drei Fällen von besonderer Bedeutung sind, da sie jeweils mit einem sehr gut erhaltenen, kompakten, direkt an die Siedlung anschließenden Terrassensystem zusammengehen, das in wirtschaftlicher Hinsicht sehr aufschlußreich ist. Eine solche Siedlung befindet sich im Nordosten unseres Forschungsgebiets beim Ort Yurtene ${ }^{54}$. Sie verfügt über sechs Häuser und um das Siedlungsareal herum über einen ausgedehnten Terrassenkomplex, der durch Flurmauern in sechs Parzellen von 1-1,7 ha geteilt ist (Abb. 14). Die Siedlung liegt auf einem hohen Plateau, das mit kleinen, dicht nebeneinander liegenden Hügeln überzogen ist. Während der Platz in der hellenistischen Zeit vermutlich nur zwei bis drei Häuser umfaßte, sind die anderen Gebäudereste aufgrund der Mauertechnik und des Keramikmaterials in die kaiserzeitliche und spätantike Epoche zu datieren.

Die zum Teil gut erhaltenen Häuser liegen regellos und ziemlich dicht beieinander. Bis auf einen großen Komplex sind die Hauseinheiten leicht voneinander zu trennen. Jedes einzelne Haus scheint über seine eigene Zisterne verfügt zu haben. Die Häuser sind einfach gestaltet: ein- oder zweiräumige Komplexe mit einem Hof bzw. einer vorgelagerten Terrasse. Die Zisternen liegen im Hof oder direkt vor dem Gebäude. Bei drei Komplexen sind außerdem Preßanlagen mit großen Preßgewichten gelegen.

Da die Gesamtzahl solcher Preßanlagen in einer Siedlung immer geringer als die der Hausreste ist - meist ein bis drei Anlagen pro Siedlung -, ist wohl anzunehmen, daß sie von mehreren Familien gemeinsam genutzt wurden. Dafür spricht, daß in der Spätantike die Zahl der Häuser anscheinend jener der Terrassenparzellen entspricht.

53 s. unten S. 246 mit Abb. 16.

54 Zu einer detaillierten Behandlung dieser Siedlung s. Verf. in: Lykische Studien 6 (2003) 5664). 


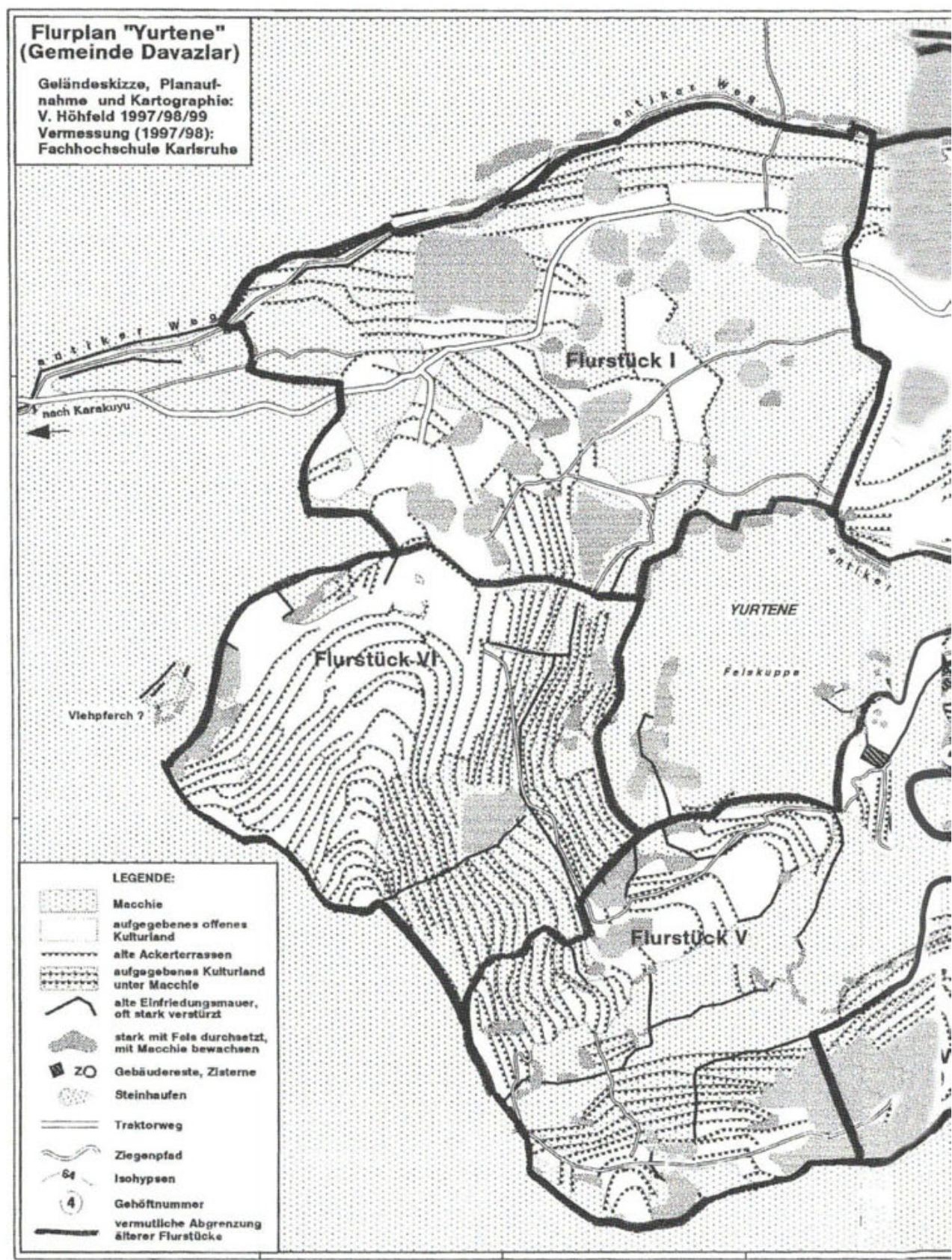




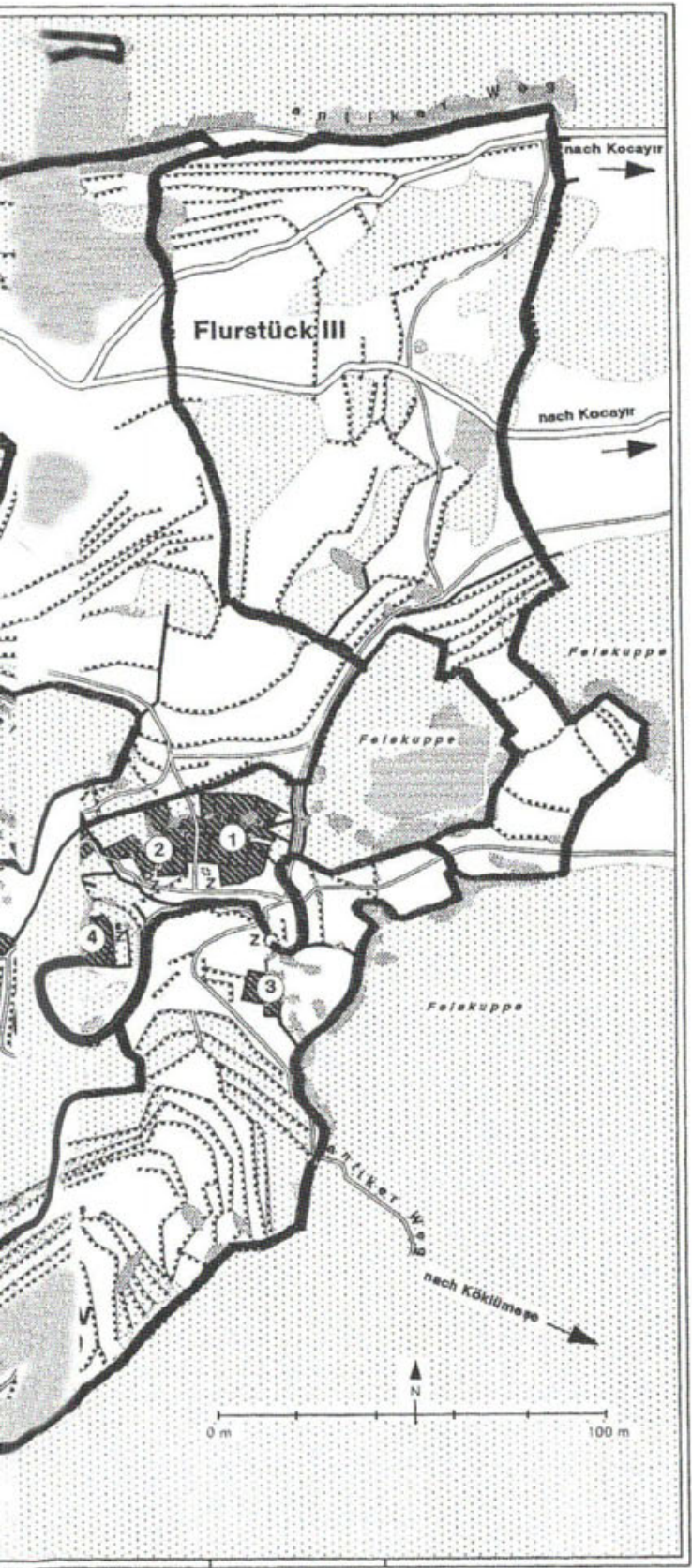

Abb. 14: Flurplan mit der Siedlung von Yurtene. 
In der Regel läßt sich die Zweckbestimmung der Pressen in unserem Forschungsgebiet nicht eindeutig einordnen. Sie bestehen oft lediglich aus einer aus dem anstehenden Fels herausgehauenen, rechteckigen Preßtenne, einem meist kreisförmigen Auffangbecken und einem rechteckigen Balkenloch in der felsigen Rückwand ${ }^{55}$. Die Größe und der Typus der Preßgewichte in der Siedlung von Yurtene rechtfertigt jedoch die Annahme, daß hier - trotz der Höhenlage von ca. $800 \mathrm{~m}$ - hauptsächlich Olivenölproduktion betrieben wurde, daneben aber vielleicht auch Weinproduktion. Auf der Oberfläche der zylindrischen Preßsteine befinden sich vom Rand quer zum Zentrum verlaufende trapezoidale Einlassungen, in welchen sich je eine weitere ovale Eintiefung befindet. Diese Preßsteine dienten dazu, einen vertikal stehenden Balken zu befestigen ${ }^{56}$. Der Stein selbst diente als Gegengewicht am anderen Ende des horizontal gelagerten Preßbalkens. Solche zylindrischen Gegengewichte werden der aus der antiken Literatur bekannten Spindelpresse zugewiesen ${ }^{57}$. Viele Exemplare von verschiedenen Gewichten für Spindelpressen sind in unserem Forschungsgebiet entdeckt worden und weisen darauf hin, daß in Zentrallykien technische Entwicklungen in großem Umfang und teilweise nebeneinander eingesetzt wurden ${ }^{58}$.

Siedlungen mit Terrassensystemen, wie jene von Yurtene, scheinen eine beachtliche Kontinuität aufzuweisen, wobei ihre Nutzung freilich in allen Fällen anscheinend vor der mittelbyzantinischen Zeit abbricht. Das Fehlen einer Kirche rechtfertigt diese Annahme. Die Blütezeit der Siedlung von Yurtene ist anhand des

${ }^{55} \mathrm{Zu}$ diesem Typ von Preßanlagen s. A. Diler, The most common wine-press type found in the vicinity of Cilicia and Lycia, in: Lykia II (1995) 83-98 insesondere Abb. 13. 14. Die Typologie der Preßanlagen in den kleinen ländlichen Siedlungen des Territoriums von Kyaneai werden in der Dissertation (im Druck) der Verfasserin ausführlicher behandelt werden. Siehe für diesen Typ Preßanlagen in der Siedlung LVI: Verf., in: F. Kolb (Hrsg.), Lykische Studien 5 (Asia Minor Studien Bd. 41) 2000, Abb. 24; 25. Zur Typologie der Preßanlagen in Lykien allgemein s. A. Konecny, Einige Ölpressen auf dem Bonda Tepesi und im Gebiet von Istlada, in: ÖJh 67 (1998) Beibl. 121-194; ders., Lykische Ölpressen II. Die Ölverarbeitungsanlagen in der Siedlung auf dem Dinek Tepesi, in: ÖJh 68 (1999) Beibl. 141-170. Die Anlagen des besprochenen Typs gehören in seiner Typologie zur Gruppe 1. Zu Preßanlagen in Lykien und im südlichen Kleinasien s. ferner $A$. Diler, Akdeniz Bölgesi antik çağ zeytinyağı ve şarap işlikleri in: Araştırma Sonuçları Toplantısı XI (1994) 505-520; ders., Akdeniz Bölgesi antik çağ zeytin ve üzüm presleri-1993 in: Araştırma Sonuçları Toplantısı XII (1995) 441-457.

56 Siehe für ein ähnliches Beispiel R. Frankel, Some oil presses from Western Galilee, BASOR 286 (1992) 66-67 Abb. 35 a2. Für die Rekonstruktion einer Presse mit einem ähnlichen zylindrischen Gegengewicht in Kafr Nabo s. O. Callot, Huileries Antiques de Syrie du Nord (Bibliothèque archéologique et historique 108, 1984) Taf. 122, 123; N. Hanel, Römische Ölund Weinproduktion auf der Iberischen Halbinsel am Beispiel von Munigua und Milreu, MM 30 (1989) 226 Abb. 10.

57 Zur Spindelpresse s. R. J. Forbes, Studies in Ancient Technology III (1955) 135-138; E. Jüngst, P. Thielscher, BJb 157 (1957) 107; N. Hanel, a.O. 214 Abb. 10. Plinius d. Ä (n.h. 18, 317) bezeugt, daß die Spindelpresse 100 Jahre vor seiner Zeit erfunden wurde. Außerdem s. Vitruv $(6,6,3)$ und Heron von Alexandria (Mechanik 3, 15).

58 Unzutreffend ist somit die gegenteilige Schlußfolgerung von A. Konecny (ÖJh Beibl. 67 (1998) 130) für Zentrallykien. Er ging nach Ergebnissen seiner Untersuchungen im Umland von Limyra davon aus, daß diese technische Entwicklung in die Landwirtschaft des antiken und byzantinischen Lykien nicht eingeführt wurde. 
Mauerstils und des auffallend zahlreichen Keramikmaterials in die kaiserzeitlichspätantike Epoche zu datieren . Die betreffenden Scherben sind an der Oberfläche häufig durch Riefen verziert.

Den überwiegenden Anteil des Keramikmaterials in kleinen Siedlungen bilden generell grobe Gebrauchsware und großformatige Vorratsgefäße; Feinkeramik spielt kaum eine Rolle. Die auffallend hohe Anzahl spätantiker Keramikfragmente in den kleinen Siedlungen legt nahe, daß sie wohl in dieser Epoche eine Blütezeit erlebt haben. Während sich für 58 der insgesamt 69 Siedlungen eine Nutzung in der Spätantike nachweisen läßt, ist bei 24 eine Siedlungskontinuität bis in byzantinische Zeit bezeugt. 21 von ihnen offenbaren ihre späte Besiedlung durch Kirchen, während bei den übrigen 3 Siedlungen eine solche Annahme durch entsprechend datierbare Oberflächenkeramik gerechtfertigt wird.

Es ist freilich zu berücksichtigen, daß das Keramikmaterial Zentrallykiens, insbesondere die Gebrauchsware, noch recht unerforscht ist, was es erschwert, die spätantike von der byzantinischen Gebrauchskeramik mit Sicherheit zu sondern. Daher könnte der Anteil der byzantinischen Keramik größer sein als zum gegenwärtigen Zeitpunkt zu belegen ist. Andererseits unterstützen Baudatierungen und das Fehlen einer Kirche in einigen in der Spätantike bewohnten Siedlungen die Annahme, daß diese im Laufe der byzantinischen Zeit aufgelassen wurden. Diese beiden Indizien, das Fehlen einer Kirche und des entsprechend datierbaren Keramikmaterials, dürften meines Erachtens zumindest einen Hinweis auf einen gewissen Rückgang der Besiedlung geben, zumal andere Siedlungen 1-3 Kirchen bzw. Kapellen aufweisen.

Es scheint generell außer Kirchen keine öffentlichen Bauten in den kleinen ländlichen Siedlungen gegeben zu haben. Daraus kann geschlossen werden, daß die Zentralortfunktionen in der Regel bei den Komenzentren zu suchen sind. Die Kirchen sind zudem meist einschiffige, relativ kleine Kapellen, die kaum als Gemeindekirchen gedient haben können. Nur in fünf Siedlungen befinden sich der frühbyzantinischen Zeit angehörende, dreischiffige Kirchen von basilikalem Charakter ${ }^{59}$. Sie haben alle eine Grundfläche von ca. $25 \times 15 \mathrm{~m}$ und zeichnen sich durch eine einfache, dreischiffige Bauform aus. In zwei Fällen sind einschiffige kleine Kapellen an die Südseite angebaut ${ }^{60}$. In der Forschung gibt es die Ansicht, daß Basiliken mit Kapellen, welche die Apsis flankieren, eine Besonderheit des frühen lykischen Kirchenbaus sind ${ }^{61}$. Während es sich bei einer der beiden

59 Von diesen fünf Basiliken befindet sich eine in der Siedlung XXVIII im Ürer-Gebiet. Eine knappe Beschreibung dieser Siedlung wurde bereits von A. Thomsen in: Lykische Studien 2 (1995) $64 \mathrm{f}$. publiziert, wobei sich die Ergebnisse der detaillierteren Untersuchungen der Hausruinen und der Basilika in diesem Vorbericht nicht finden, sondern erst in der Dissertation der Verfasserin präsentiert werden. Weitere Basiliken liegen in der Siedlung XXXI im Ayıbeleni-Gebiet (s. K. Geppert in: Lykische Studien 3 (1996) 83-86 Abb. 26), in der Siedlung XLII bei Büyük Avşar, in der Siedlung L in Kocaboynuz (s. Verf. in: Lykische Studien 4 (1998) $67 \mathrm{ff}$. Abb. 25), und in der Siedlung LXXIX in Çürüt.

${ }^{60}$ Die Basiliken in der Siedlung XXXI und in der Siedlung L (s. o. Anm. 59) weisen kleine angebaute Kapellen auf.

61 U. Peschlow, Spuren des byzantinischen Mittelalters in Lykien in: J. Borchbardt, G. Do- 
Kirchen um eine solche an das Seitenschiff angebaute und wohl gleichzeitig entstandene Kapelle handelt, ist die Kapelle der zweiten Kirche im ehemaligen Seitenschiff errichtet worden. Sie stammt deswegen höchstwahrscheinlich aus einer späteren Phase der Siedlung. Beim Wiederaufbau von Kirchen in Lykien wurden viele nicht in der alten Gestalt wiedererrichtet, sondern durch den Einbau einer kleinen Kirche in die Ruine des Vorgängerbaus ersetzt ${ }^{62}$.

Schmuckelemente deuten darauf hin, daß die Innenausstattung zumindest in einigen Fällen durchaus reich war (Abb. 15). Solche Fragmente wurden auch in zwei kleinen einschiffigen Kirchen des Forschungsgebietes gefunden ${ }^{63}$. Die meist aus dem lokalen Kalkstein herausgearbeiteten Stücke gehören in der Regel zu Altarschranken. Sie stammen alle aus der frühchristlichen Phase und tragen zur Datierung der Siedlungsphasen bei.

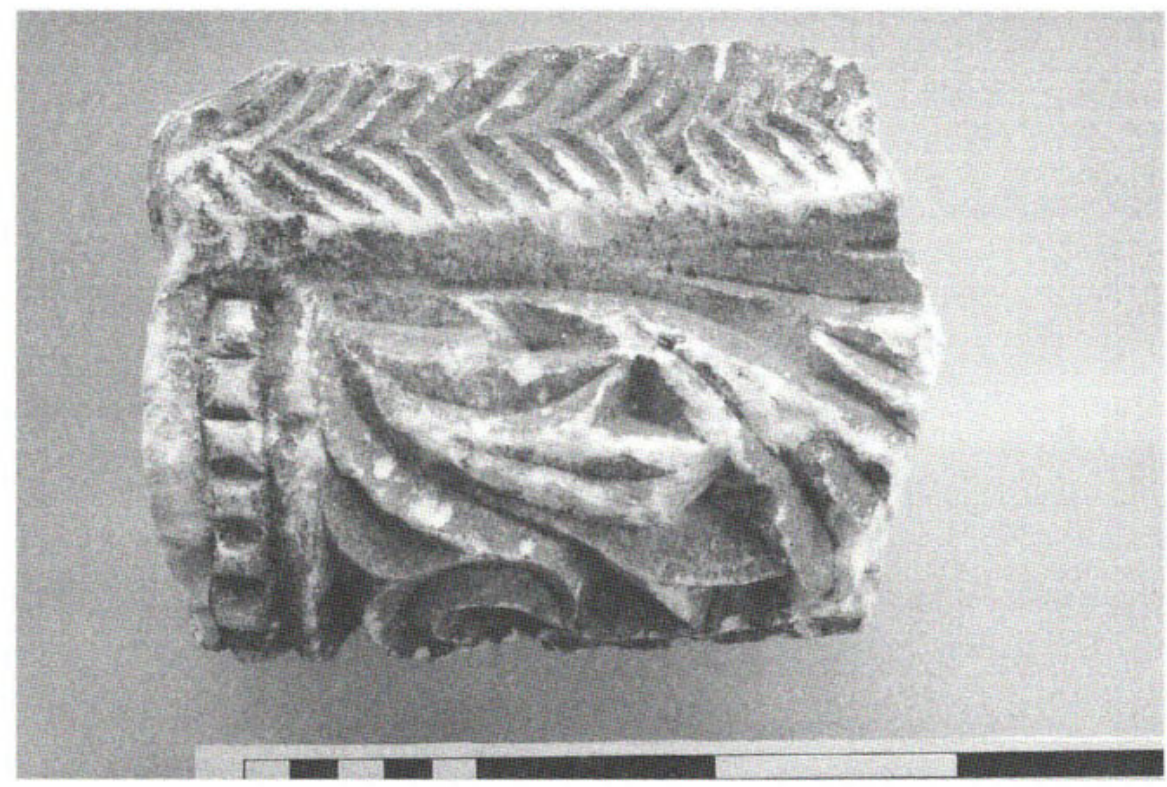

Abb. 15: Bauornamentik aus der Basilika in Siedlung XXVIII.

besch (Hrsg.), II. Lykien-Symposion, Bd. II (1993) $61 \mathrm{~m}$. Anm. 23; Vgl. auch R. M. Harrison, Churches and Chapels of Central Lycia, AnatSt 13 (1963) 149.

62 U. Peschlow, a. O. 62. Eine Besonderheit ist hier jedoch, daß die Kapelle nicht im Mittelschiff, sondern im Seitenschiff plaziert ist.

${ }^{63}$ Es handelt sich hier um die Kirche in der Siedlung LXVII bei Hidirlar und um die Kirche (Befund Nr. 10410) bei Karakuyu. Es ist freilich nicht auszuschließen, daß diese Schmuckelemente ursprünglich zu den Vorgängerbauten bzw. zu früheren dreischiffigen Basiliken gehörten. 
Eine zeitliche Einordnung der kleinen einfachen Kirchen ohne solche Funde bildet dagegen ein problematisches Unterfangen. Weil diese oft nur aus einfachem Bruchsteinmauerwerk mit Mörtel errichtet wurden, fehlen mauertechnische Kriterien für die Datierung. Byzantinisches Keramikmaterial innerhalb des Siedlungskontextes, das manchmal bis zur spätbyzantinischen Phase reicht, läßt nicht zu, die Entstehungszeit dieser einfachen Kirchenbauten zu bestimmen; es bietet allenfalls Hinweise auf den Nutzungszeitraum sowohl der Siedlung als auch ihrer Sakralbauten.

Manche solcher Orte, die eine byzantinische Nutzungsphase mit Kirche aufweisen, waren vom Hellenismus an bis in die osmanische bzw. türkische Zeit besiedelt. Allerdings ist es schwer auszumachen, ob womöglich zwischen den verschiedenen Phasen Besiedlungslücken vorgekommen sind. Da ein zentrales Problem der Landwirtschaft im Gebiet von Kyaneai der Mangel an ackerbaufähigen Flächen war, spielte die Nähe der Ansiedlung zu fruchtbaren Böden besonders bei längerer Besiedlungszeit eine große Rolle.

Darüber hinaus ist es auffallend, daß in manchen Gebieten dieser Region die Siedlungen in byzantinischer Zeit recht dicht beieinander liegen, während in anderen Gegenden Besiedlungslücken vorgekommen zu sein scheinen. Die dichtesten Ansammlungen, insbesondere der etwas größeren dorfartigen Siedlungen können wir in der unmittelbaren Nähe von Kyaneai sowie im Umfeld von Komenzentren, wie Büyük Avşar und Hoyran, feststellen. Es scheint, daß die byzantinische Besiedlung sich um bestimmte Ortschaften konzentrierte.

Eine byzantinische Siedlung liegt z. B. nördlich von Hoyran, direkt südwestlich unterhalb der oben besprochenen klassischen Siedlung von Divle (Abb. 16). Sie erstreckt sich am nordwestlichen Rand einer Ebene, die heute von den Einwohnern von Divle für den Getreideanbau genutzt wird.

Die Tatsache, daß insbesondere byzantinische Siedlungen meist direkt am Rand fruchtbarer Ebenen gegründet worden sind, zeigt wohl, daß der Getreideanbau in späteren Zeiten bei der landwirtschaftlichen Produktion der Siedlungen ein wichtige Rolle gespielt hat. Daß zugleich aber die Olivenöl- oder Weinproduktion genauso wichtig blieb wie in kaiserzeitlich-spätantiker Zeit, scheint die Existenz dreier Preßanlagen in dieser Siedlung und zweier weiterer in der Umgebung anzuzeigen.

Außer den Preßanlagen fanden sich in dieser Siedlung eine einschiffige Kirche, ca. 12 Hauskomplexe, acht Zisternen und einige Einzelräume, die vermutlich als Wirtschaftsräume dienten.

Die Haustypen in den Siedlungen scheinen sich von der klassischen bis in byzantinische Zeit wenig geändert zu haben. Zudem scheinen sie stark von der Topographie abhängig gewesen zu sein. Die einzige bemerkenswerte Entwicklung ist, daß die im flachen Gelände gelegenen Häuser mancher byzantinischen Siedlungen komplexer werden, wie in letztem Beispiel, und mehr dem Gehöfttypus zu ähneln beginnen, obwohl auch Hanghäuser mit einer vorgelagerten Terrasse, die für frühere Siedlungen charakteristisch sind, in allen Epochen unverändert vorkommen. 


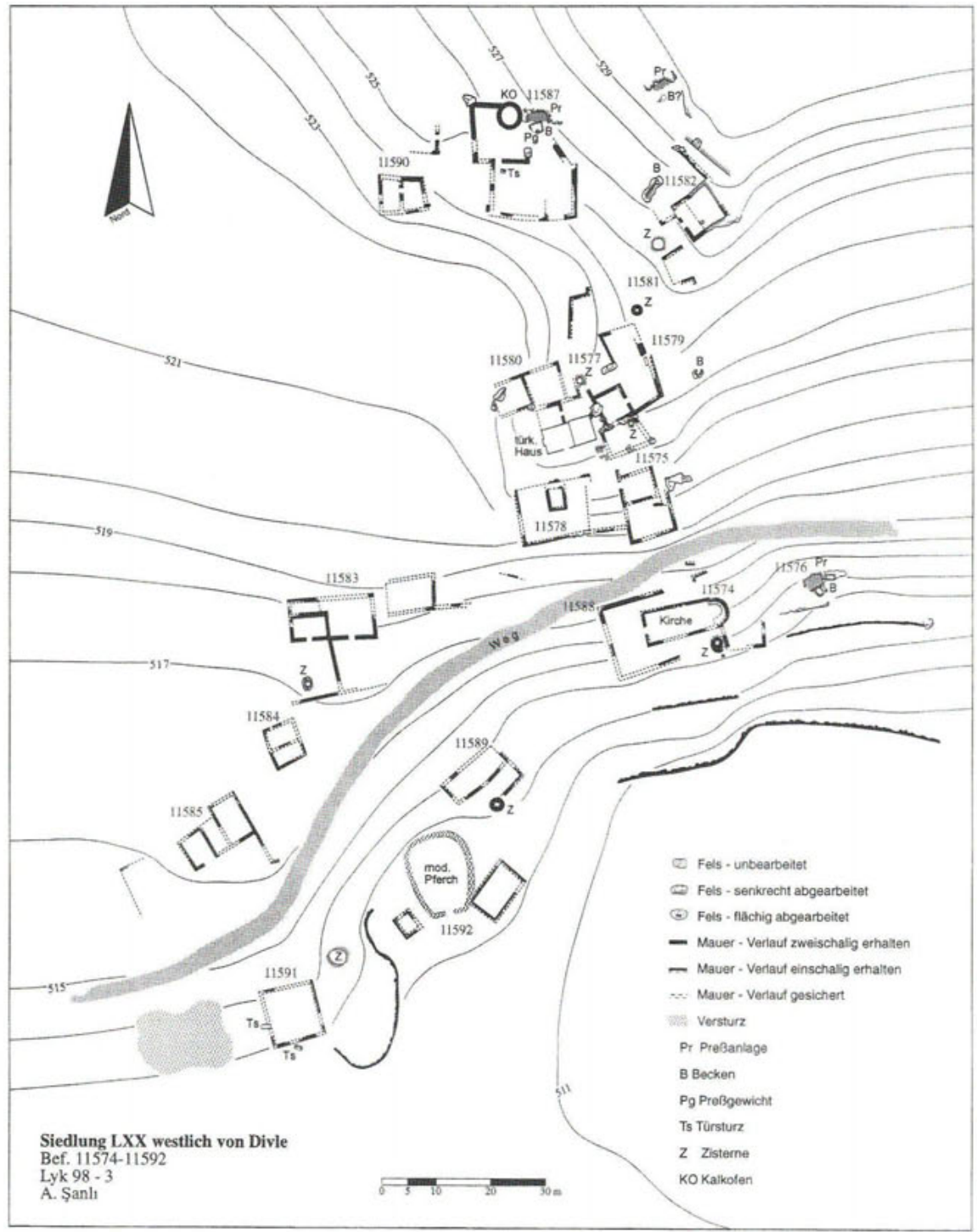

Abb. 16: Plan von Siedlung $L X X$ westlich Divle. 
Während der Großteil der byzantinischen wie auch der kaiserzeitlichen und spätantiken Siedlungen eine Fläche von 0,5 bis 1 ha umfaßt, ist sie bei einigen dorfähnlichen Siedlungen, deren Schwerpunkt in byzantinischer Zeit liegt, deutlich größer. Sie schwankt hier zwischen 1 und 3,5 Hektar.

Die Einwohnerzahl dürfte in den meisten Siedlungen mit durchschnittlich fünf Häusern zwischen 20-40, bei größeren Siedlungen mit 14-15 Häuser bei etwa 60-100 Personen gelegen haben.

Siedlungsgrößen

\begin{tabular}{lr}
\hline $3-5$ Häuser & 38 Siedlungen \\
$5-10$ Häuser & 19 Siedlungen \\
$10-15$ Häuser & 7 Siedlungen \\
Häuserzahl unbestimmbar & 5 Siedlungen
\end{tabular}

Angesichts der wenig sorgfältigen Bautechnik und der recht einfachen Gebäudetypen darf man annehmen, daß die Bewohner solch kleiner Dörfer in allen Epochen einfache Bauernfamilien waren. Das ist auch daraus zu schließen, daß dort nur sehr selten Sarkophage anzutreffen sind. Man hat mit größter Wahrscheinlichkeit sehr bescheidene Gräber gebaut, welche heute wegen ihrer einfachen Ausführung - wahrscheinlich schlichte Erdbestattungen - nicht mehr zu erkennen sind.

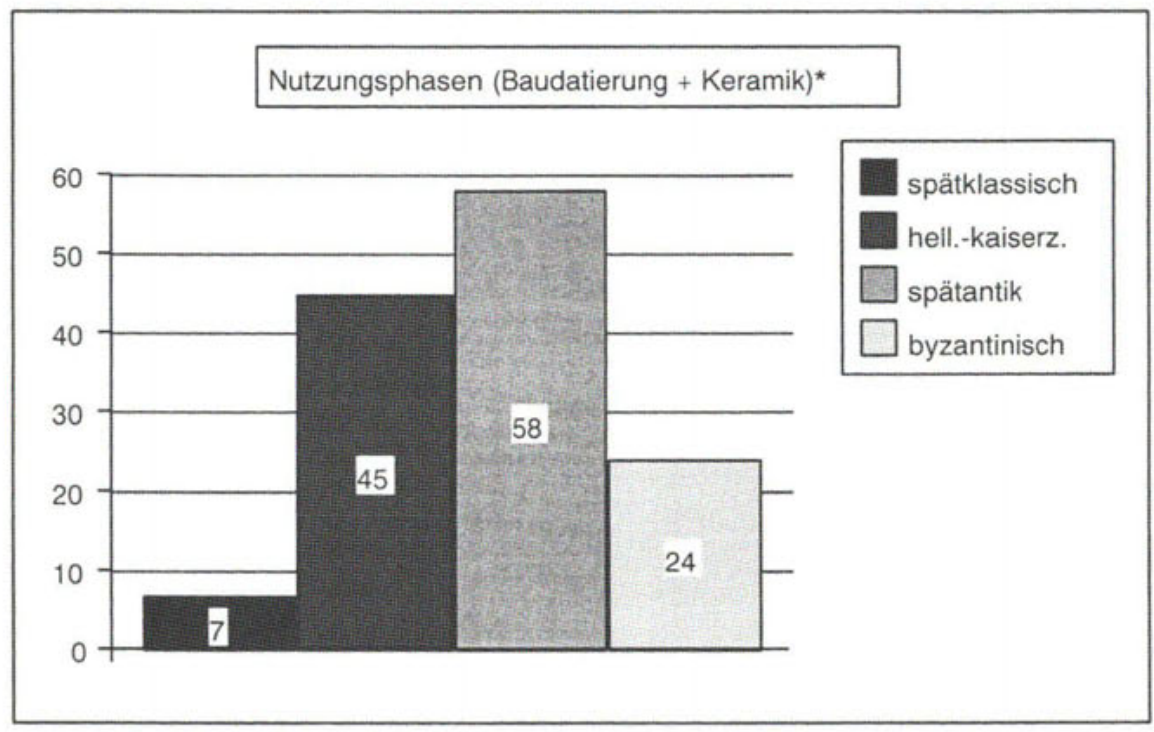

Abb. 17 Nutzungsphasen ("Dieses Diagramm entspricht dem derzeitigen Auswertungsstand der Befunde). 
Wenn man die chronologische Entwicklung der Siedlungsstruktur im gesamten Territorium beobachtet, so ist nach heutigem Stand festzustellen, daß den Großteil der ländlichen Besiedlung in der archaisch-klassischen Zeit Einzelgehöfte bildeten, während kleine ländliche Siedlungen zu dieser Zeit noch recht selten sind. $\mathrm{Ab}$ der hellenistischen Zeit sehen wir eine Entwicklung bzw. eine Änderung sowohl hinsichtlich der topographischen Situation als auch der Zahl der ländlichen Siedlungsplätze. Die Hügelkuppe als Siedlungsplatz wird sowohl bei Einzelgehöften als auch bei den Siedlungen nicht mehr bevorzugt. Die Gehöfte bzw. Siedlungen werden ab jetzt an den Hängen der Hügel, oberhalb einer fruchtbaren Ebene, errichtet. Während die Türme der Turmgehöfte in der hellenistischen Zeit und vielleicht auch weiterhin in römischer Zeit eine gewisse Schutzfunktion für die um sie gruppierten Siedlungen boten, wurden die Siedlungen in spätantik/ byzantinischer Zeit direkt in der Ebene ohne jegliche Schutzmaßnahmen errichtet. Dies legt die Schlußfolgerung nahe, daß agrarwirtschaftliche Bequemlichkeit gegenüber dem Sicherheitsbedürfnis in den Vordergrund trat und die Verteidigungsmaßnahmen zentralisiert, d.h. auf die bedeutenderen Ansiedlungen verlagert wurden.

Dabei ist eine von der gleichmäßig verteilten Siedlungsweise zur Siedlungskonzentration tendierende Entwicklung festzustellen. Dies belegt deutlich die Verödung mancher .Gebiete in spätantik-byzantinischer Zeit und die zunehmend dichte Ansammlung von Siedlungen um größere Siedlungszentren wie um die Polis Kyaneai und um die Komenzentren herum. 